ارزيابى صفات زراعى و تحمل به خشكى در لاينهاى حاصل از سه تلاقى بين گونهاى گلرنگ

سهيلا اسينانى'، محمدمهدى مجيدى ‘*، قدرتاله سعيدى"، حسين علايى و وحيد رضايى"

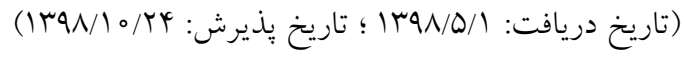

حكيده

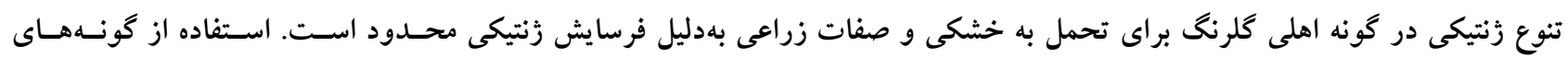

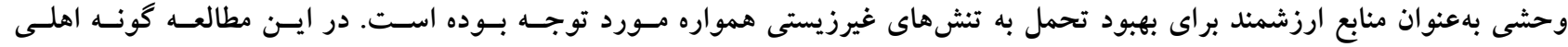
(Carthamus tinctorius)

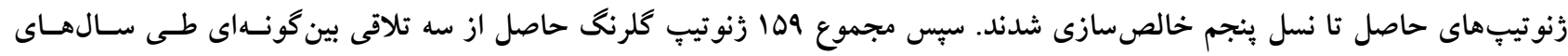

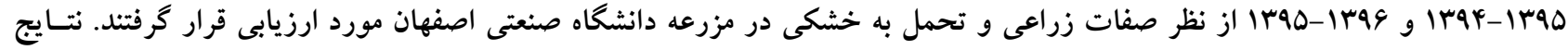

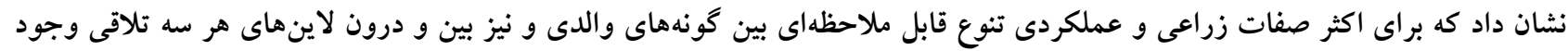

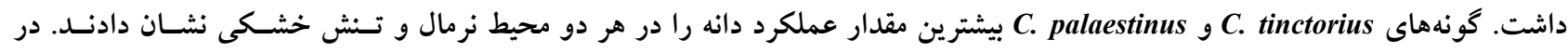

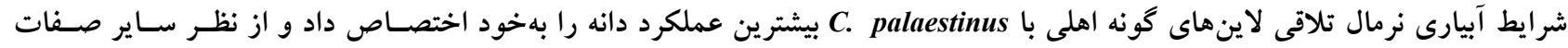

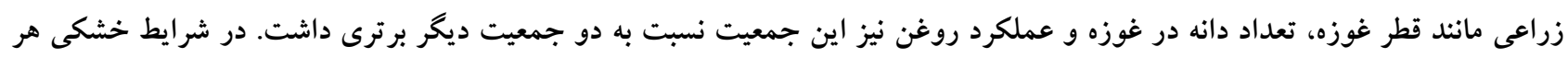

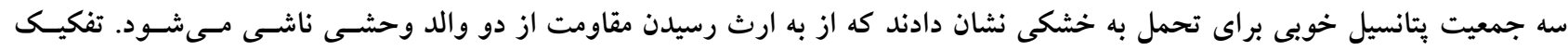

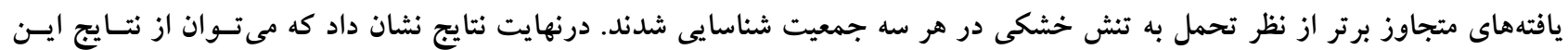

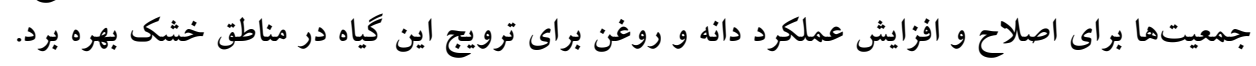

وازههاى كليدى: تلاقىهاى بين گونهاى، تنش خشكى، عملكرد دانه، گلرنخ

ا، r و r. به ترتيب دانشجوى دكترى، استادان و فارغ التحصيلان كارشناسى ارشد، كروه زراعت و اصلاح نباتات دانشكده كشاورزى، دانشعاه صـنعتى

اصفهان، اصفهان، ايران.

majidi@cc.iut.ac.ir : مسئول مكاتبات: بِّت الكترونيكى إنى 


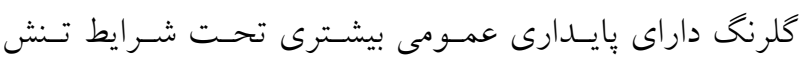

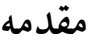

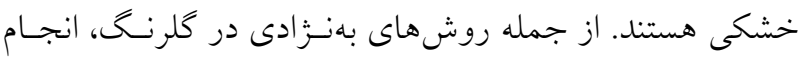
هيبريداسيون بين كونهاى و سبس انتخاب در بين نتايج در حسال

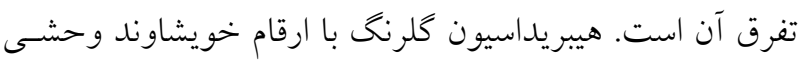

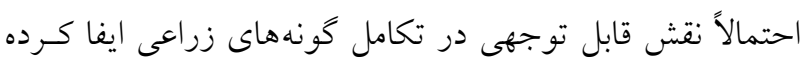

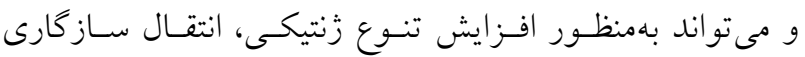

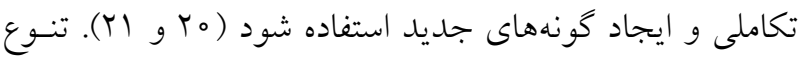
زننيكى درون كونه زراعى گلرنخ محدود است؛ امـا كونسهـاى

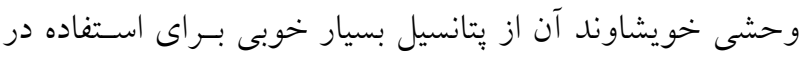

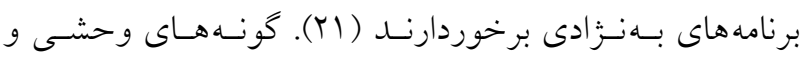

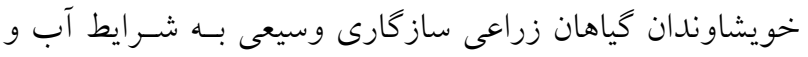
هو ايى مختلـف دارنــــ و حامـل زنهــاى مفيـدى هسـتند. ايسن

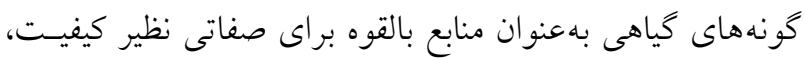

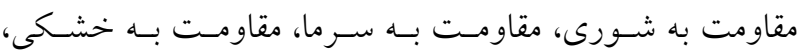

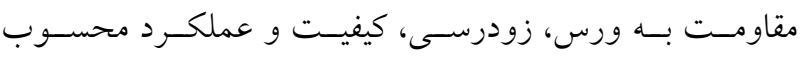

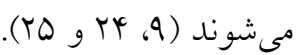

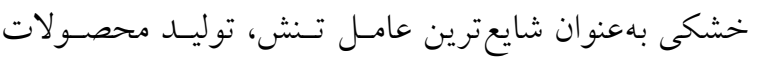
كشاورزى را در حدود هr درصد از اراضى دنيا محدود كـرده و

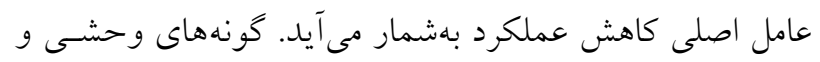

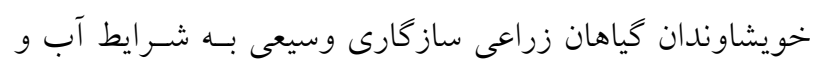

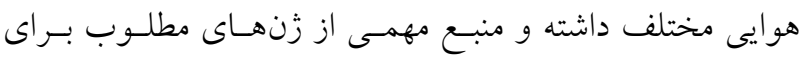

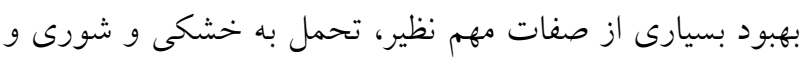
افزايش عملكرد محسوب مسىشـوند (9). مجيسـى و همكــاران

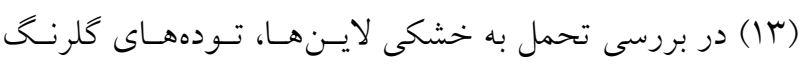

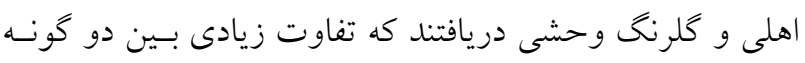

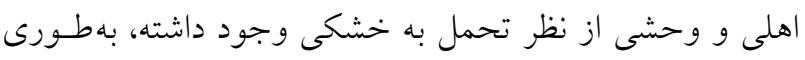

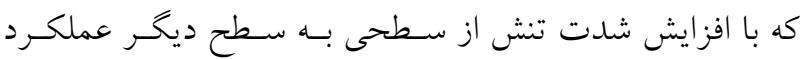

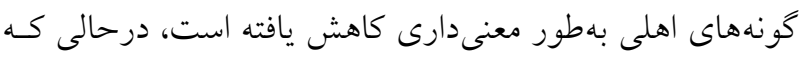

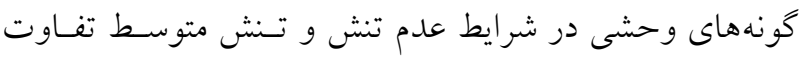

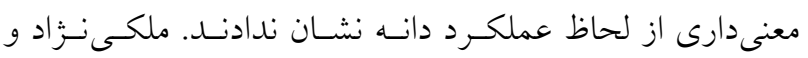

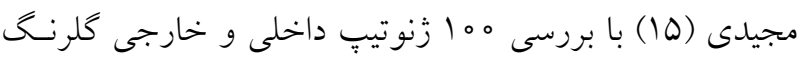

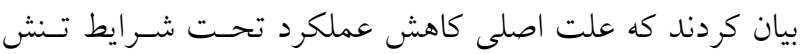

با وجود توليد سالانه صد هزار تن روغن خام در كشور كه تنهـا

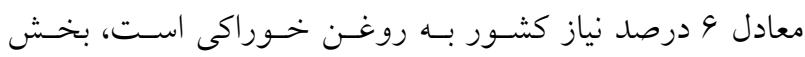

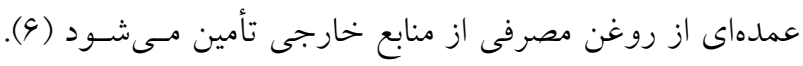

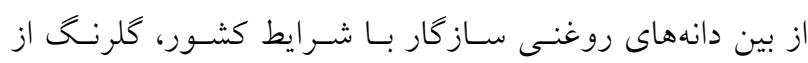

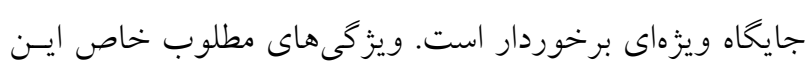

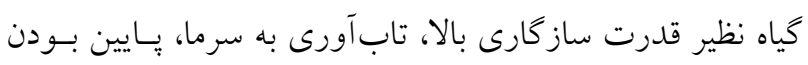

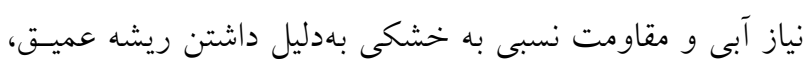

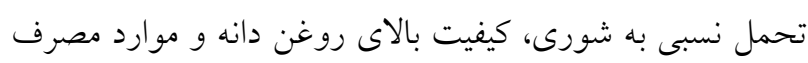

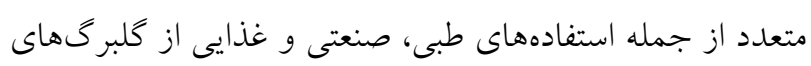

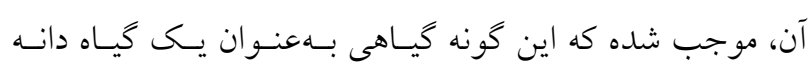

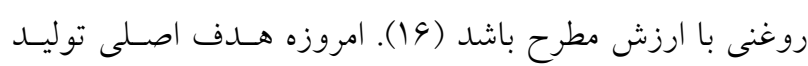

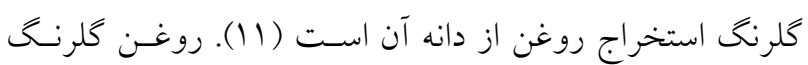

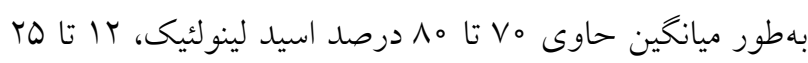

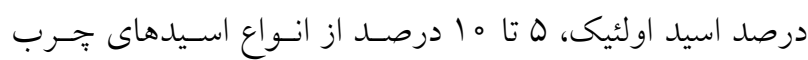

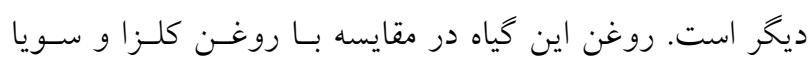

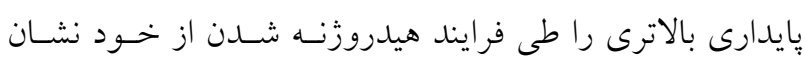

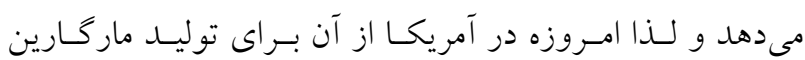

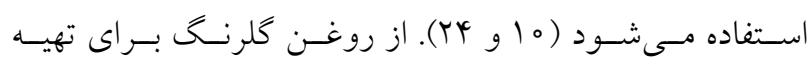

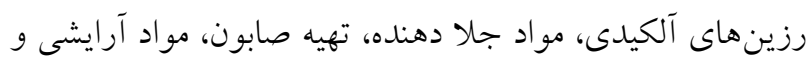

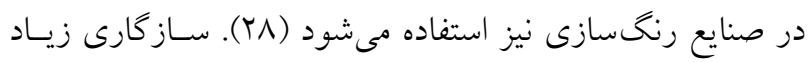

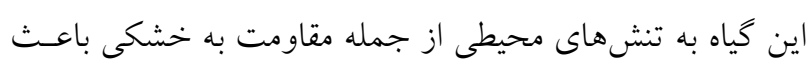

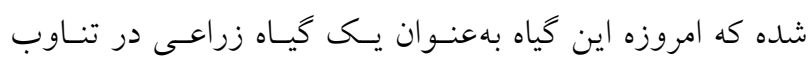

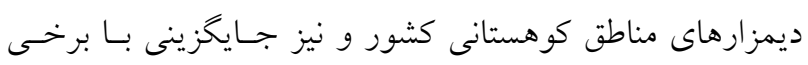
كياهان با مصرف آب بالا داراى اهميت باشند.

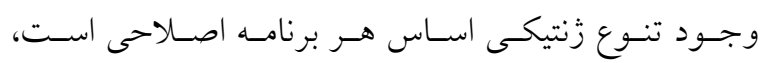

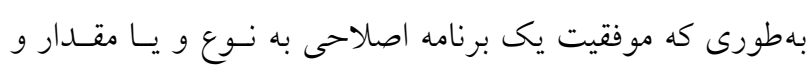

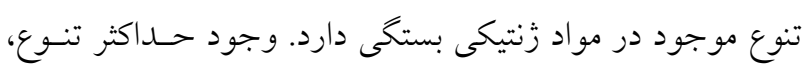

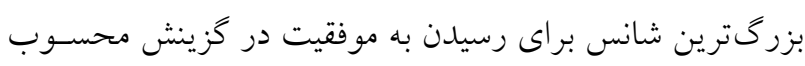

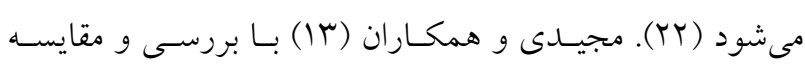

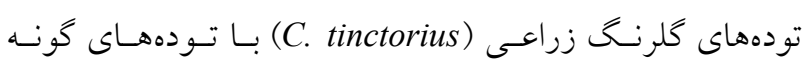

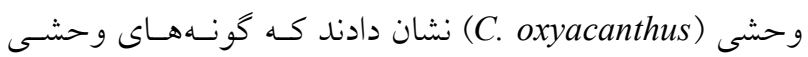




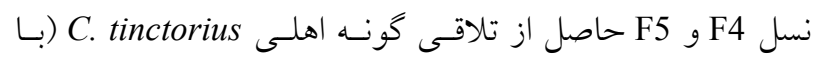

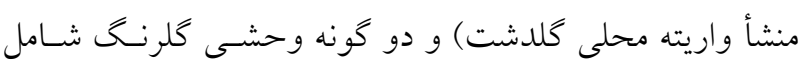
C. palaestinus

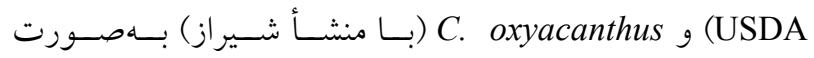
$\times$ C. oxyacanthus ، C. tinctorius $\times$ C. palaestinus (TP) C. oxyacanthus $(\mathrm{PO}) \times$ C. palaestinus،(TO) C. tinctorius

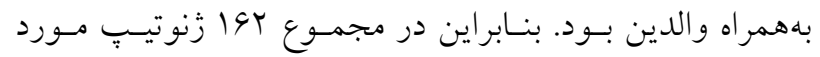

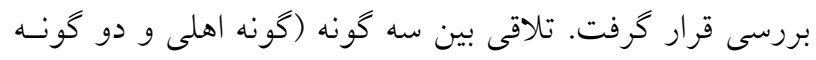

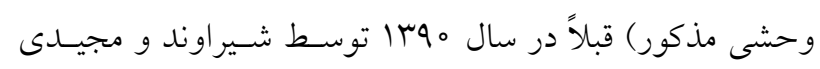

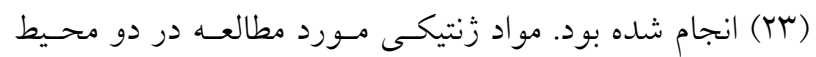

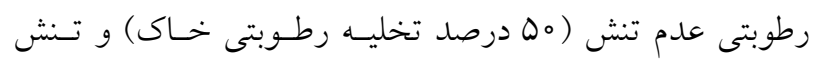

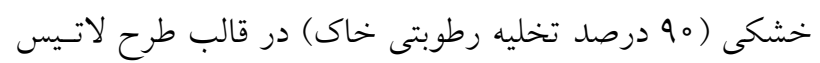

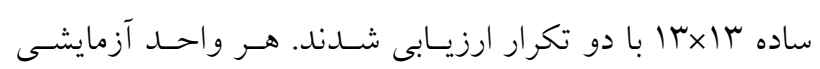

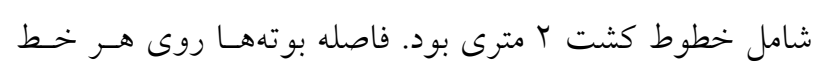

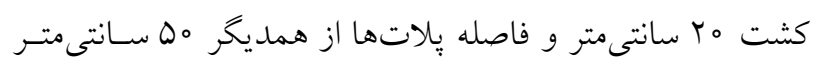

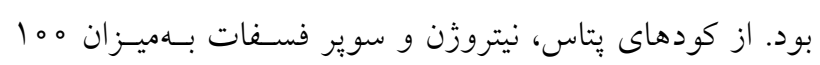

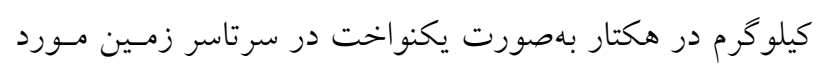
آزمايش استفاده شد.

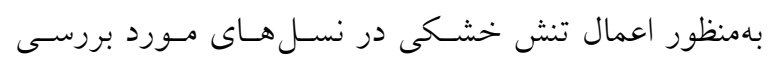
تمامى كرتها تا •ه درصد تكمهدهى از نظــ آبيـارى و اعمـال مديريتهاى زراعى بهصورت يكسان درنظر كرفته شد. در زمان أنهان

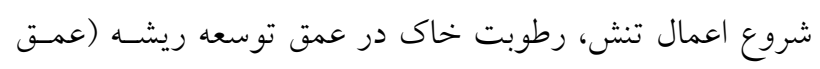

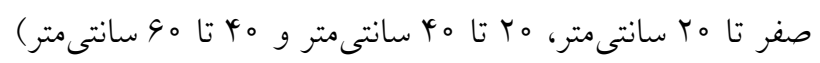

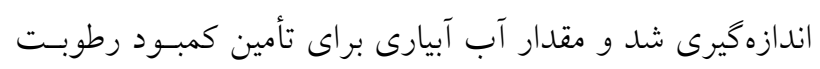

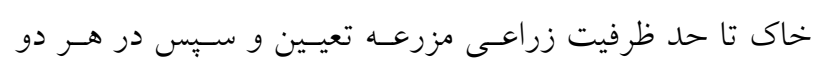

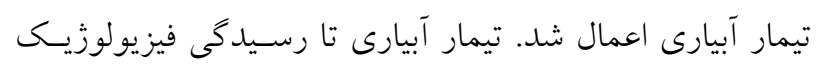

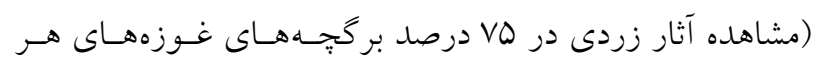

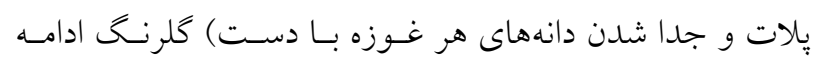

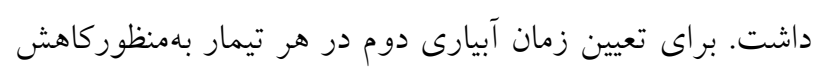

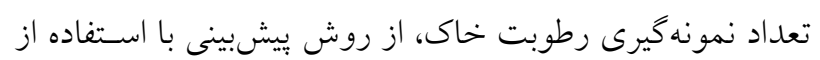

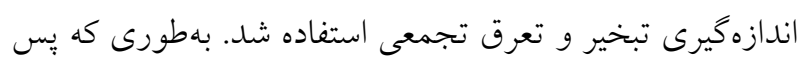

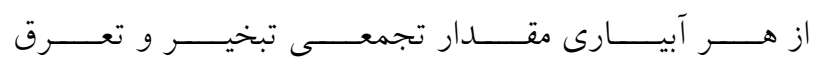

خشكى، كاهش تعداد غوزه در بوته است و بيشترين ميزان تنوع

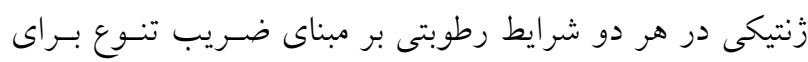

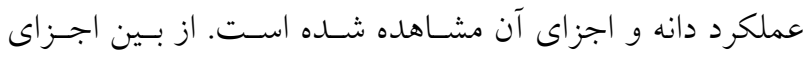
عملكرد دانه، تعداد غوزه در بوتهه و وزن هـز وار دانسه در تعيسين

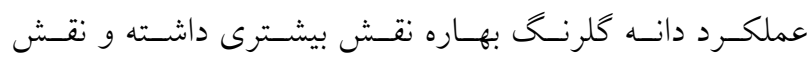

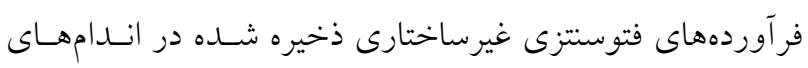

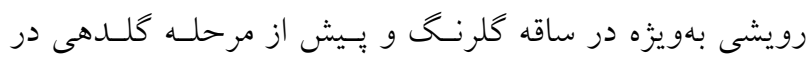

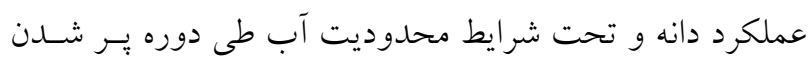

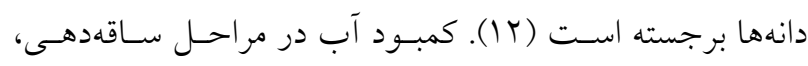

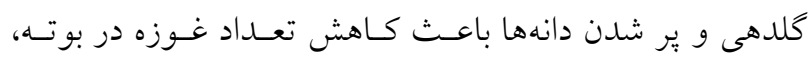

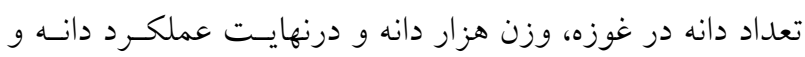
روغن در كلرنخ بهاره شده است (A).

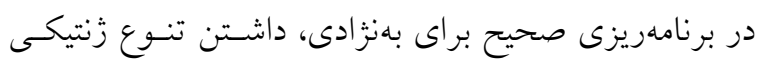

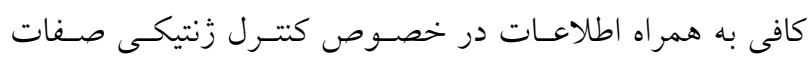

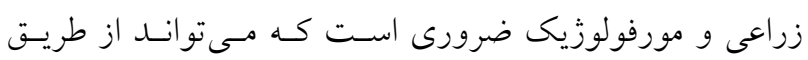
بررسى تلاقى هاى بين كونهاى حاصل شود. از آنجايى كه بيشـتر

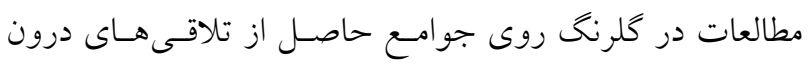

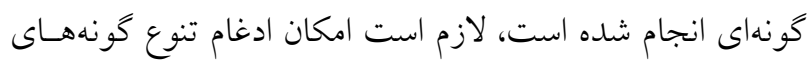

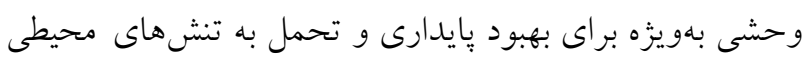

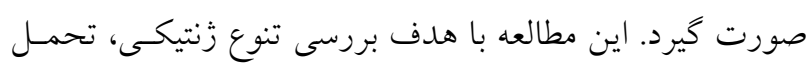

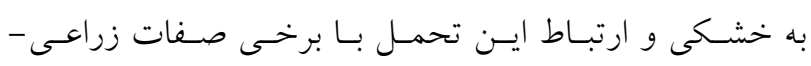

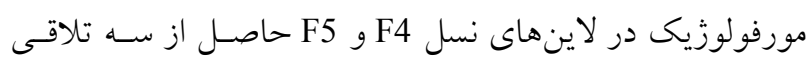

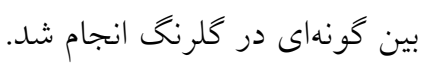

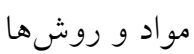

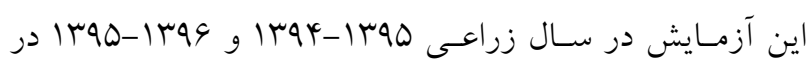

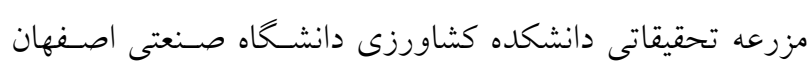

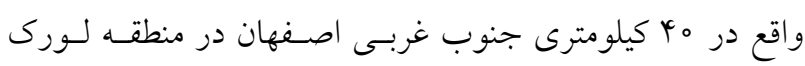

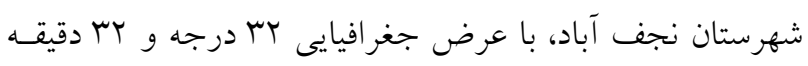
شمالى و طول جغرافيايى اله درجسه و ساب دقيقـه شـرقى انجـام

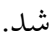
مواد زنتيكى مورد استفاده در اين مطالعه شامل مه زنو زنيب 
جدول ا. سودمندى نسبى طرح بلوى كامل تصادفى نسبت به طرح لاتيس در دو نسل F4 و F5 در دو محيط آبيارى نرمال و تنش خشكى

\begin{tabular}{|c|c|c|c|c|c|c|c|c|c|c|}
\hline OY & SY & $\mathrm{O}$ & SW & SH & HD & HP & NB & $\mathrm{DM}$ & محيط & نسل \\
\hline $10 Y / \Lambda F$ & 1. & $100 \%$ & $100 / \Delta Y$ & $10 Y / \Delta T$ & $100 / 01$ & $100 / 91$ & $10 \mu / \mu_{0}$ & $10 V / T Q$ & نرمال & $\mathrm{F} 4$ \\
\hline $91 / 49$ & $91 / V \Lambda$ & $99 / \circ \mathrm{H}$ & $101 / 90$ & $100 / 01$ & $100 / 10$ & $100 / V 9$ & $10 V / \Lambda G$ & $119 / 01$ & خشكى & \\
\hline $10 Y / \circ 4$ & $10 Y / T V$ & $110 / \mu^{\prime}$ & $10 Y / / Y$ & $9 \Lambda / N r$ & $10 Y / \backslash \Lambda$ & $\| k / \mu \mid$ & $100 \%$ & $1.1 / 100$ & نرمال & F5 \\
\hline $100 / 11$ & $100 / \Delta r$ & $101 / V 9$ & $10 \Delta / r_{0}^{\circ}$ & $101 / V 9$ & $|\mu| / \mu \mid$ & $100 / 0 r$ & $100 / T V$ & $|r \& / Y|$ & خشكى & \\
\hline
\end{tabular}

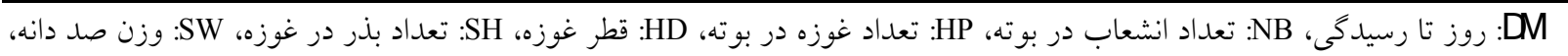

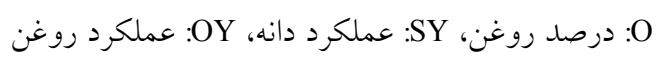

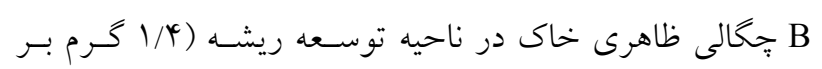

$$
\text { سانتى متر مكعب) است. }
$$

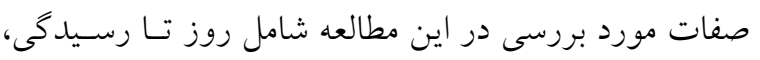

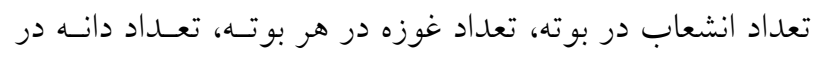

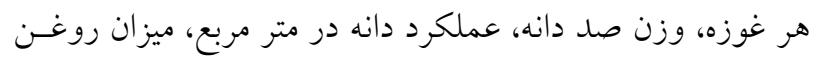

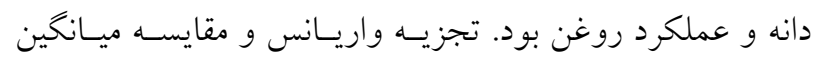

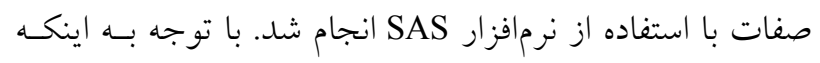

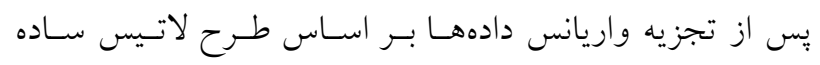

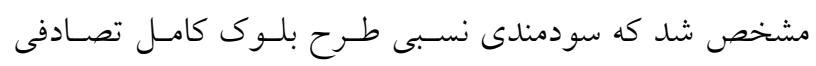

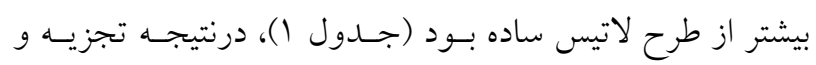
تحليل آمارى دادهها بنصورت طرح بلوى كامل تصادفى انجـام كرفت.

\section{نتايج و بحث}

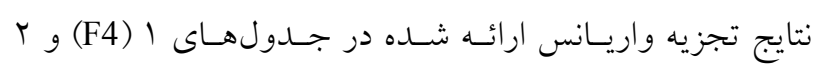

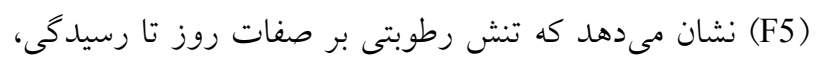

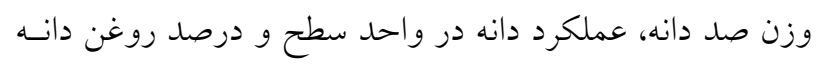

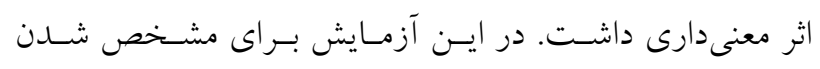

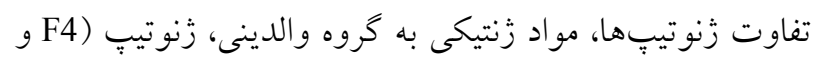

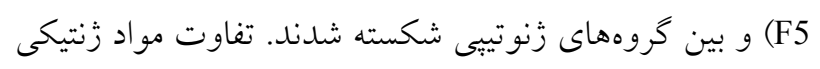

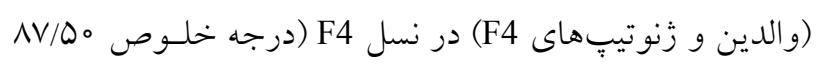

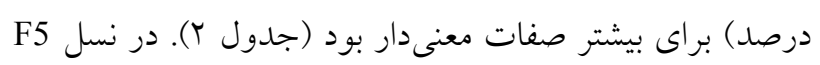

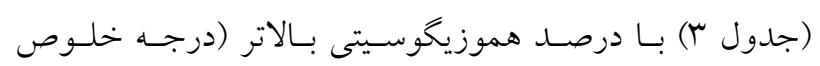

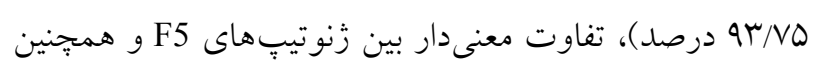

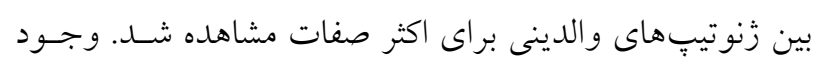

(ETc)

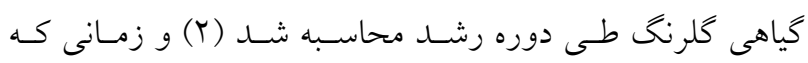

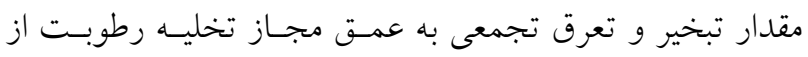

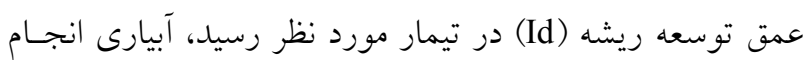

ليكن براى اطمينان از عدم اعمـال تـنش در تيمـار شـاهد و

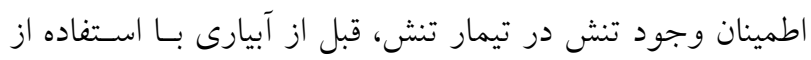

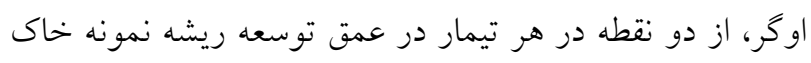

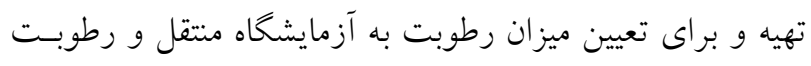

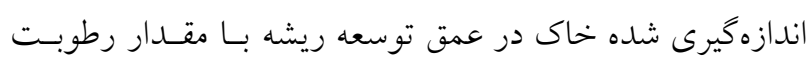

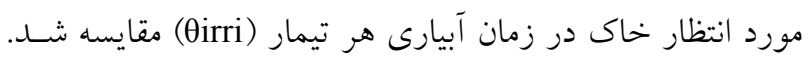

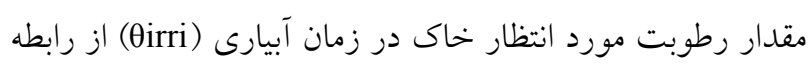
زير محاسبه مىشود:

$[\theta$ irri $=\theta$ fc- $[(\theta \mathrm{fc}-\theta$ pwp $) \times$ MAD

بنابر اين زمان آبيارى براى تيمارهاى مختلف متفاوت خواهد بود

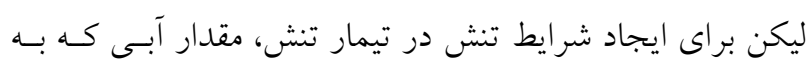

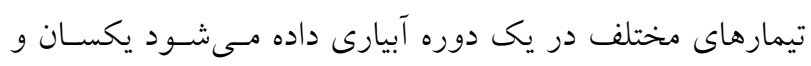

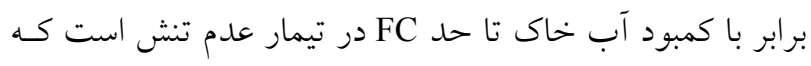
مقدار آن از رابطه زير محاسبه مىشود: $\mathrm{I}=($ FC- $\theta$ irri $) \times \mathrm{D} \times \mathrm{B}$

در رابطه فوق Oirri متوسط رطوبت وزنى خاك در عمق توسعه

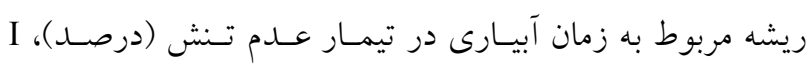

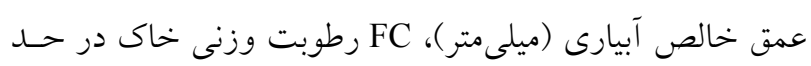

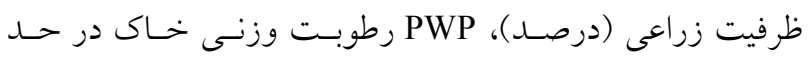

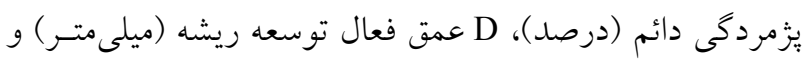




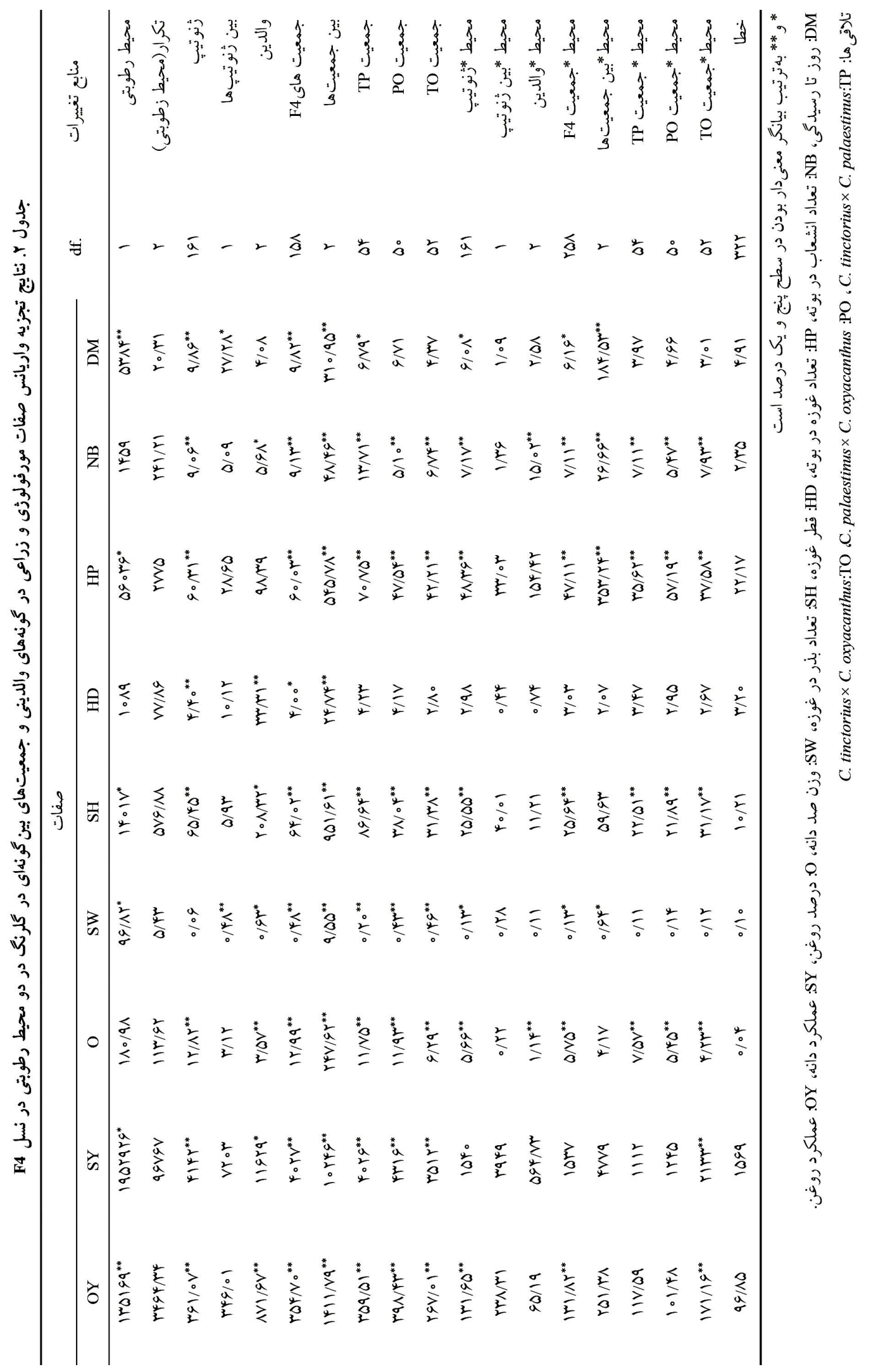




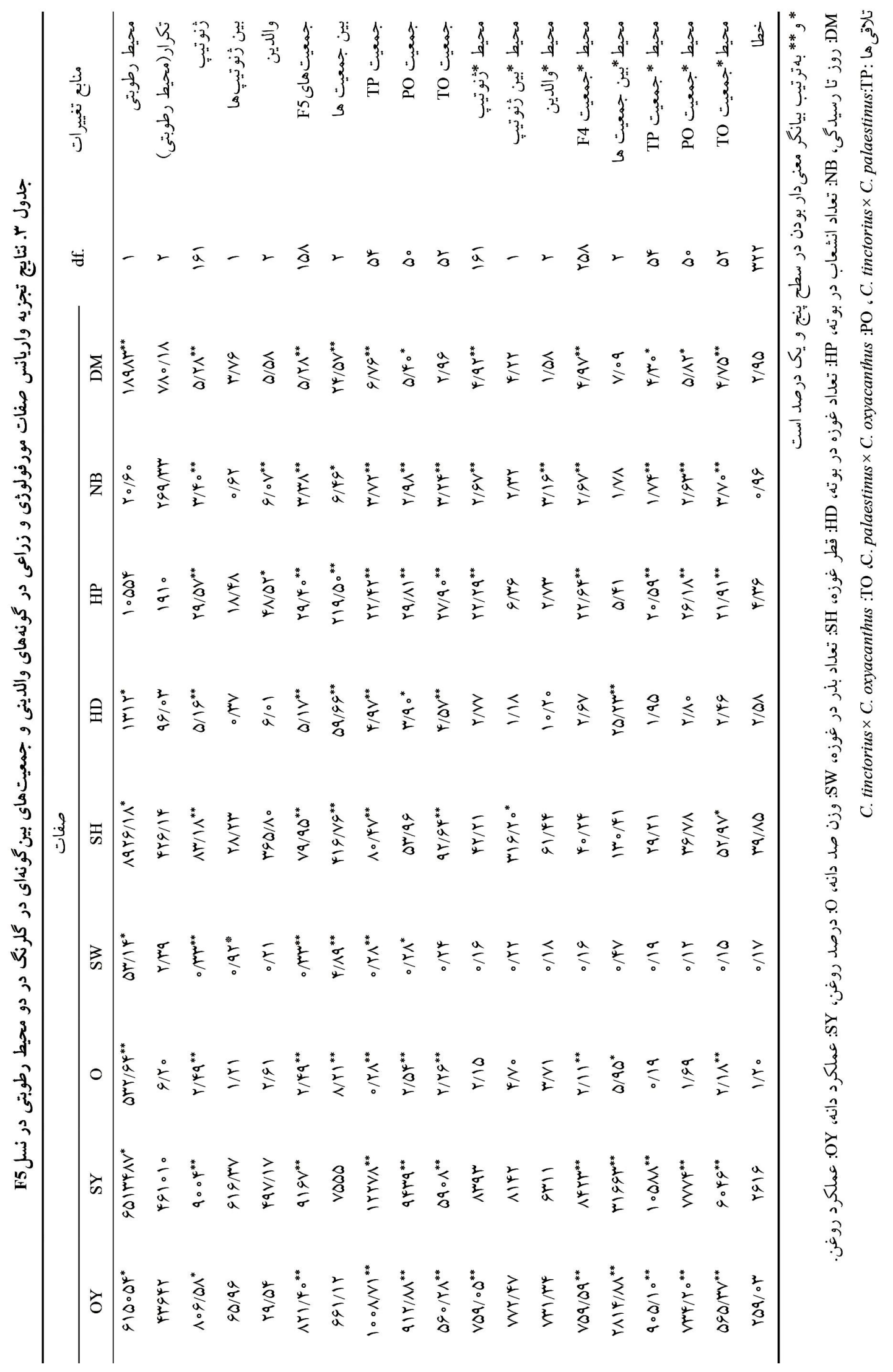


جدول F. مقايسه ميانگين شرايط آييارى نرمال و تنش خشكى بر صفات مورفولوزيك و زراعى براى جمعيتهاى بين گونهاى

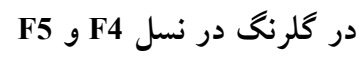

\begin{tabular}{|c|c|c|c|c|c|c|c|c|c|c|}
\hline \multicolumn{9}{|c|}{ صفات } & \multirow{2}{*}{ محيط } & \multirow[b]{2}{*}{ نسل } \\
\hline $\begin{array}{c}\mathrm{OY} \\
\left(\mathrm{gm}^{-2}\right)\end{array}$ & $\begin{array}{c}\mathrm{SY} \\
\left(\mathrm{gm}^{-2}\right)\end{array}$ & $\begin{array}{c}\mathrm{O} \\
(\%)\end{array}$ & $\begin{array}{l}\text { SW } \\
(\mathrm{g})\end{array}$ & $\mathrm{SH}$ & $\begin{array}{c}\mathrm{HD} \\
(\mathrm{mm})\end{array}$ & HP & NB & $\begin{array}{c}\mathrm{DM} \\
\text { (day) }\end{array}$ & & \\
\hline ON/MTa & $r \Psi \circ / N V^{a}$ & $r Q / 1 \varphi^{a}$ & $r / 9 T^{a}$ & $r Q / \varphi_{0} a$ & $r \mid / 9 \circ a$ & $M / \Delta \varphi^{a}$ & $10 / \wedge \varphi^{a}$ & $1 \pi r / 9 V^{a}$ & نرمال & \\
\hline$r q / r \Delta^{b}$ & $|r| / 9 \circ b$ & $r y / l \circ^{a}$ & $r / 1 q^{b}$ & $19 / \pi V^{b}$ & $1 \Lambda / 9 \Lambda^{a}$ & $10 / \mu r^{b}$ & $V / \wedge q^{a}$ & $\mid r \wedge / \backslash Q^{b}$ & خشكى & $\mathrm{F} 4$ \\
\hline$k 9 / 01$ & $\uparrow V / \backslash \Lambda$ & $Y / r 1$ & $r G / T \Lambda$ & $r G / 40$ & $\mid r / T$ & $\Delta Y / T \Delta$ & $T V / T O$ & $\mu / \mu r$ & درصد تغيير & \\
\hline $9 Y / 0 Y^{a}$ & $\mu \circ \Lambda / \circ \gamma^{a}$ & r。/००a & & $r V / M^{a}$ & $r \mu / l r^{a}$ & $19 / 10^{a}$ & $9 / 09^{a}$ & $\mid r r / 9 q^{a}$ & نرمال & \\
\hline$r \Lambda / I T^{b}$ & $99 / \circ \Delta^{b}$ & $r N / 19^{a}$ & $Y / N Y^{b}$ & $19 / 19^{b}$ & $r \circ / / V^{b}$ & $\mathrm{~V} / \mathrm{N})^{\mathrm{a}}$ & G/Tya & $\mid T Y / 9 \Delta^{\mathrm{b}}$ & خشكى & F5 \\
\hline $90 / 09$ & $9 \mathrm{~V} / \mathrm{AY}$ & $9 / 0 r$ & IV/AT & $r \Lambda / 90$ & IT/VG & $01 / 49$ & $Y / \Lambda \Lambda$ & $\Lambda / T G$ & درصد تغيير & \\
\hline
\end{tabular}

در هر ستون و هر نسل ميانخين هايى كه داراى حداقل يك حرف مشترى هستند برمبناى آزمون LSD در سطح احتمال ه درصد تفاوت معنى دارى ندارند.

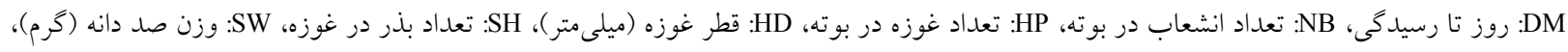

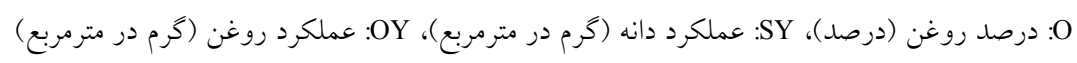

مانند ايران شناخته شده است ولى كاهش در عملكـرد دانـه آن،

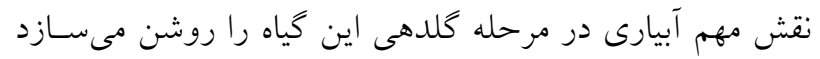

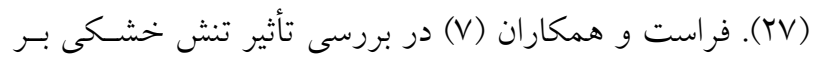

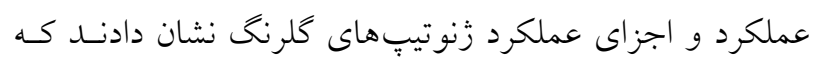

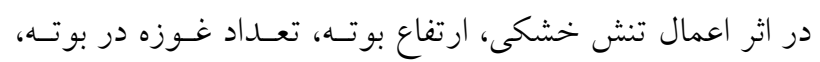

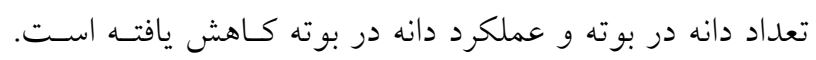

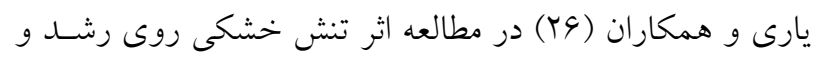

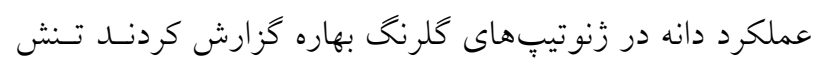

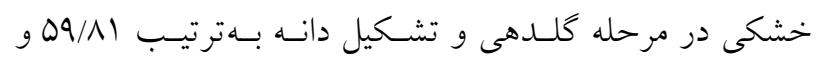

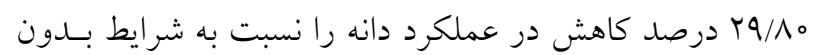
تنش به همر اه داشته است.

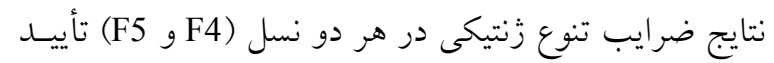

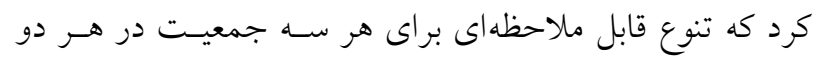

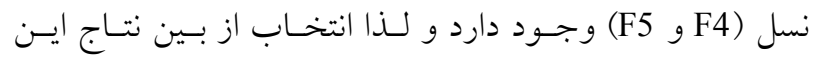

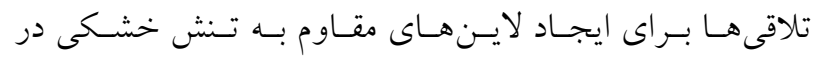

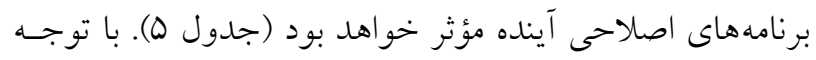

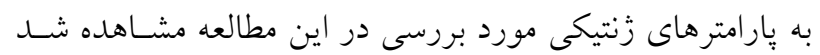

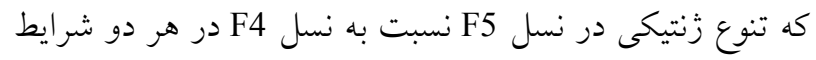

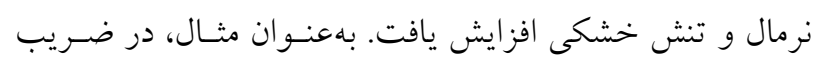

تفاوت معنى دار بين زنوتيبهاى والدينى نشان از تنسوع زنتيكى

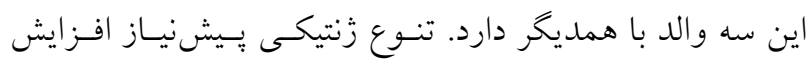
شانس گزينش زنوتيبهـاى برتسر و تفكيكى صـفات گونـاكون

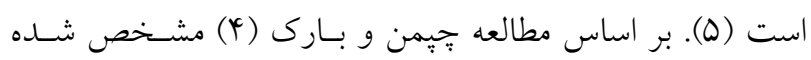

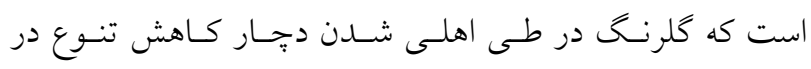

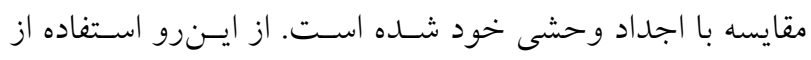

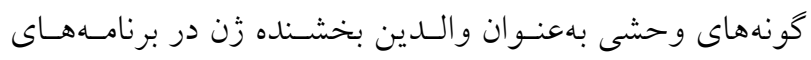

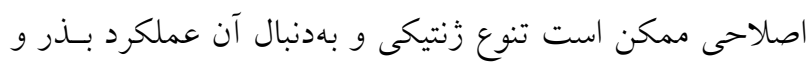

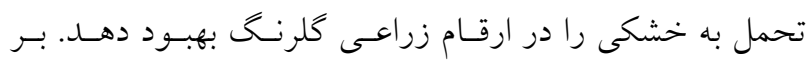

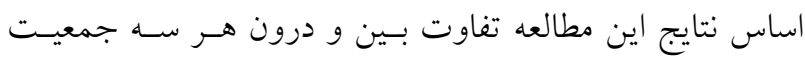

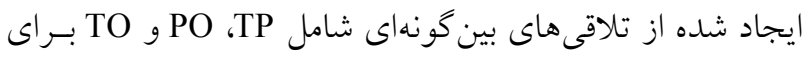

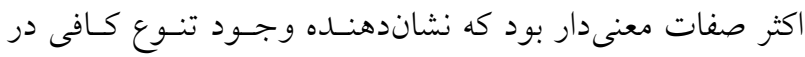

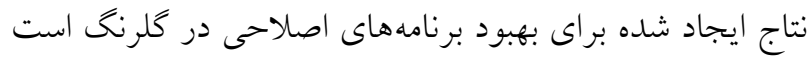

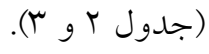
نتايج مقايسه ميانخين صفات براى محيطهاى رطوبتى نشـان داد

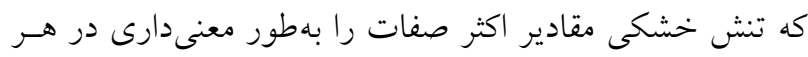
دو نسل F4 و F5 كاهش داد (جدول Y). درصد كاهش عملكرد

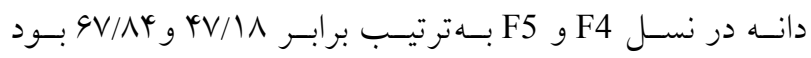

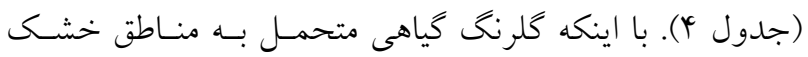


جدول ه. ضريب تنوع رُنتيكى صفات مورفولوزى و زراعى در جمعيتهاى تلاقى بين گونهاى در شرايط نرمال و تنش خشكى در نسل

F5 F4

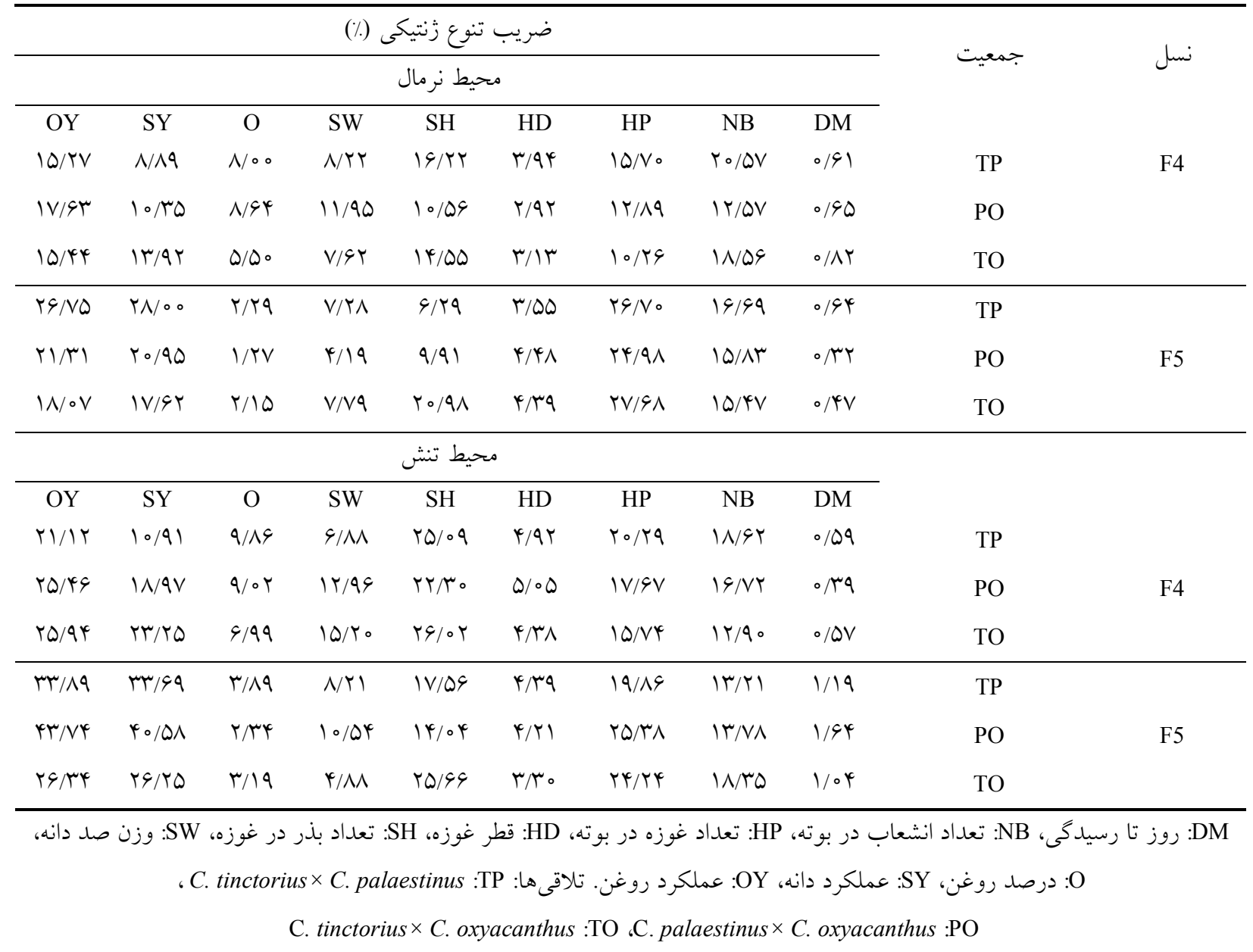

زنتيكى در نسل F5 و در برخى جمعيتها مشاهده شد. بـهنسوان

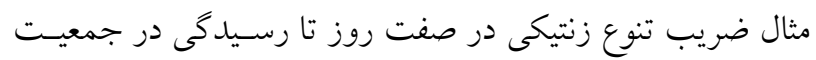

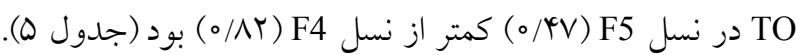
اين كاهش تنوع در برخى صفات در نسلهاى بيشرفته مسى توانــ نشان از كترل زنى غالبيت براى صفت مدنظر باشد.

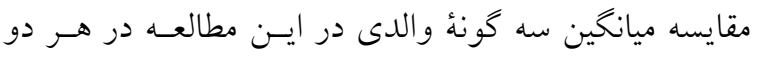
شرايط نرمال و تنش خشكى در جدول 9 نشان داده شده است.

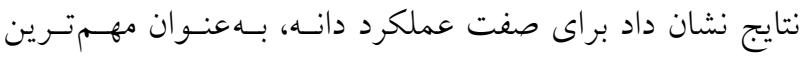
صـت اقتصـادى، C. palaestinus و C. tinctorius در هـر دو

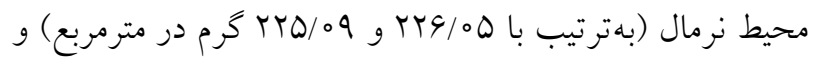

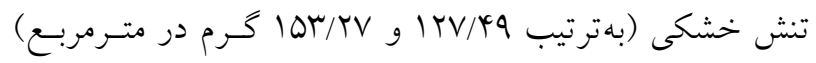

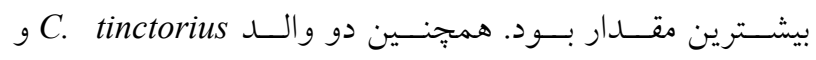

تنوع زنتيكى در شرايط نرمال براى عملكرد دانسه در نسـل F4 در

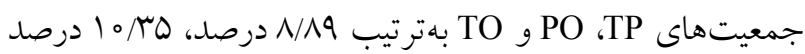

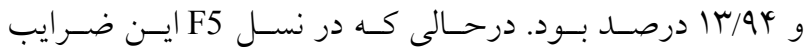

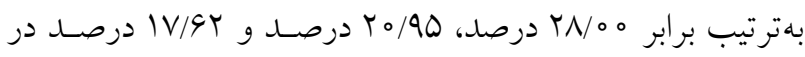
جمعيت هاى ذكر شده بود. در طول نسل هـاى متنـاوب واريـانس زَنتيكى بـين فاميـلهـا افـزايش و واريـانس درون فاميـل كـاهش مى يابد. افزايش واريانس بين فاميل ها بـهدليـل افز ايش واريـانس افزايشى و كاهش واريانس غالبيت است و بههمين دليل واريـانس

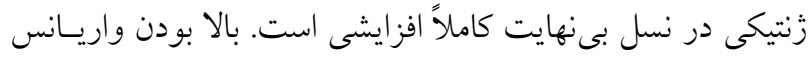
نسل F5 نسبت به دو نسل ديخر نيـز در ايسن مطالعه نيـز ممكـن

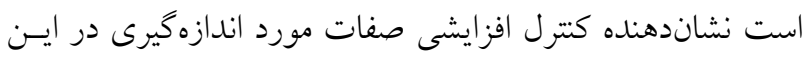

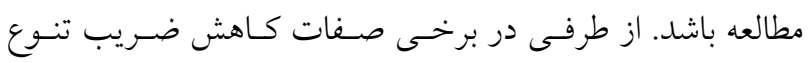




\begin{tabular}{|c|c|c|c|c|}
\hline ميانخين & خشكى & 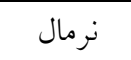 & والدين & صفات \\
\hline $1 Y N / D_{\circ} a^{a}$ & $1 \times 9 / 0^{\circ}$ & $1 \mu \circ / 0 \circ a$ & $\mathrm{~T}$ & \\
\hline$\| \mu \circ / 0 \circ a$ & $\mid r V / \circ \circ^{a}$ & $\mid r y / \circ o^{a}$ & $\mathrm{P}$ & روز تا رسيدگى (روز) \\
\hline $1 Y q / V Q^{a}$ & $1 Y V / D \circ a$ & $\mid r r / \circ o^{a}$ & $\mathrm{O}$ & \\
\hline $\mathrm{N} / \mathrm{ob}^{\mathrm{b}}$ & $\Lambda / \vee Q^{a}$ & $V / T Q^{b}$ & $\mathrm{~T}$ & \\
\hline$N / 1 Y^{b}$ & $\Delta / \circ \circ a$ & $11 / r Q^{\mathrm{a}}$ & $\mathrm{P}$ & تعداد انشعاب در بوته \\
\hline $10 / 1 r^{a}$ & $9 / 0 \circ a$ & $11 / r \Delta^{\mathrm{a}}$ & $\mathrm{O}$ & \\
\hline$r Y / Y \omega^{a}$ & $10 / \mu_{\circ} a$ & $r q / r_{\circ} a$ & $\mathrm{~T}$ & \\
\hline$\Lambda N / \Delta V^{a}$ & $19 / N \Delta^{a}$ & $r \circ / Y_{\circ} \circ$ & $\mathrm{P}$ & تعداد غوزه در بوته \\
\hline$r \Lambda / q^{a}$ & $\mid y / Y_{\circ} a$ & $Y Y / \Delta \Lambda^{a}$ & $\mathrm{O}$ & \\
\hline$r I / / l^{\mathrm{a}}$ & $19 / \mathrm{Vycab}$ & $r r / Y q^{a}$ & $\mathrm{~T}$ & \\
\hline$r \circ / 90^{\mathrm{a}}$ & 19/1 $\mathrm{r}^{\mathrm{a}}$ & $r Y / \circ V^{a}$ & $\mathrm{P}$ & قطر غوزه (mm) \\
\hline $19 / 0 \mathrm{rb}^{\mathrm{b}}$ & $1 \% / \circ V^{b}$ & $1 \wedge / \circ \circ^{a}$ & $\mathrm{O}$ & \\
\hline$r Q / / r^{2}$ & $T Y / / r^{\prime a}$ & $r G / 1 r^{a}$ & $\mathrm{~T}$ & \\
\hline$r \varepsilon / r q a$ & $r \mu / \circ \circ^{a}$ & $r q / \Delta V^{a}$ & $\mathrm{P}$ & تعداد دانه در غوزه \\
\hline $1 \% / T \Delta^{b}$ & $q / \circ \circ b$ & $I V / D \circ b$ & $\mathrm{O}$ & \\
\hline$r / 4 I^{b}$ & $1 / 19^{a}$ & $r / q \mu^{b}$ & $\mathrm{~T}$ & \\
\hline$r / \wedge V^{a}$ & $r / 19 a^{a}$ & $r / \Delta a^{a}$ & $\mathrm{P}$ & وزن صد دانه (g) \\
\hline$Y / \circ \Lambda^{b}$ & $|/ N|^{\mathrm{a}}$ & $r / 4 \& b$ & $\mathrm{O}$ & \\
\hline$r Q / Y V^{b}$ & $T Y / D \circ b$ & $r G / Y Q^{\mathrm{a}}$ & $\mathrm{T}$ & \\
\hline$r Q / \wedge V^{a}$ & $r Q / \varphi_{\circ} a^{a}$ & $r \& / / Q^{b}$ & $\mathrm{P}$ & درصد روغن (\%) \\
\hline$Y Y / \circ V^{c}$ & $Y \Psi / / Q^{b}$ & $Y Y / \circ \circ^{c}$ & $\mathrm{O}$ & \\
\hline$I V G / V^{a}$ & $\mid r V / 4 q^{a}$ & $T Y G / \circ D^{\mathrm{a}}$ & $\mathrm{T}$ & \\
\hline $1 \wedge 9 / 1 \wedge^{\mathrm{a}}$ & $\mid Q Y / r V^{a}$ & $r Y Q / \circ q^{a}$ & $\mathrm{P}$ & عملكرد دانه (gm \\
\hline$q \circ / r_{\circ} b$ & $q 4 / q Y^{b}$ & $110 / v q^{b}$ & $\mathrm{O}$ & \\
\hline $\mid r Q / T)^{a}$ & rl/ora & $\Delta 9 / Y_{\circ} \circ a$ & $\mathrm{~T}$ & \\
\hline$\uparrow \wedge / \Lambda Y^{c a}$ & $r q / \circ \Delta^{a}$ & $\Delta / / 9 \mu^{a}$ & $\mathrm{P}$ & عملكرد روغن (gm-2) \\
\hline$r I / 9 V^{b}$ & $10 / V_{0} b$ & $\mathrm{rV} / \mathrm{Nl}^{\mathrm{a}}$ & $\mathrm{O}$ & \\
\hline
\end{tabular}

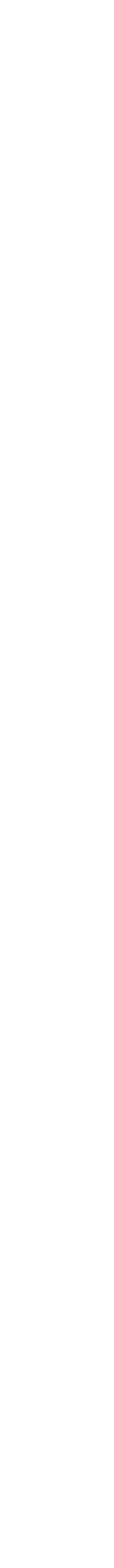


مختلف عامل برترى بودهاند. در نسل F4 جمعيت TP بـالاترين

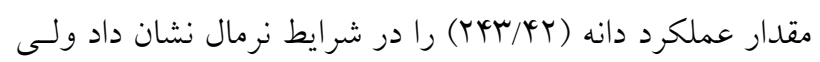

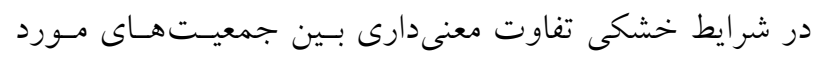

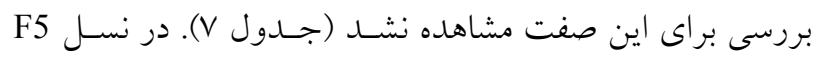

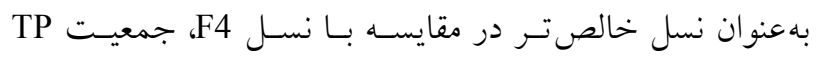

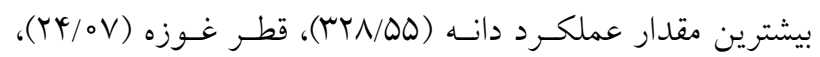

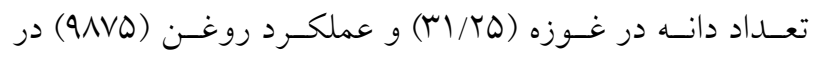

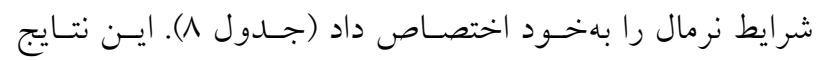

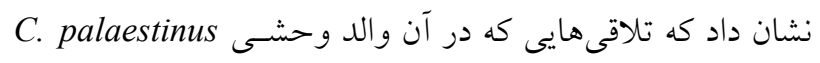

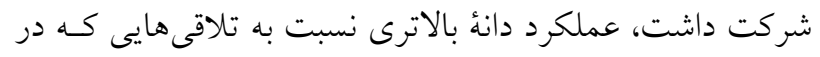

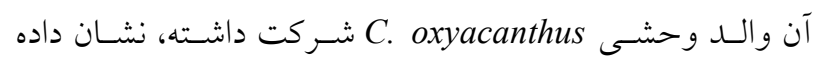
است. در شرايط تنش خشكى در نسل F5 براى صفت عملكـرد

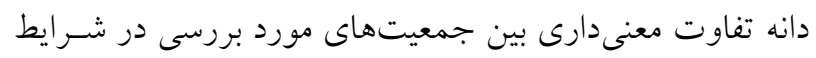

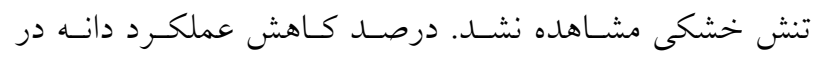

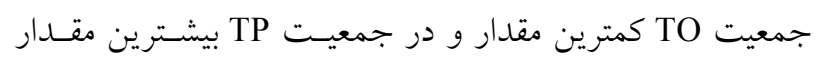

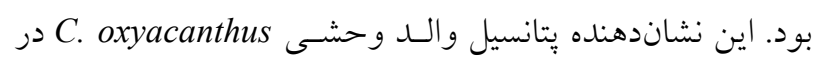

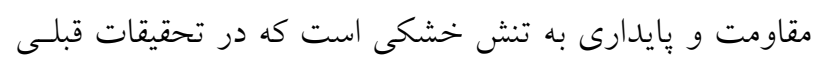

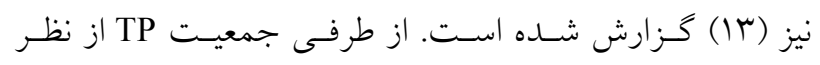

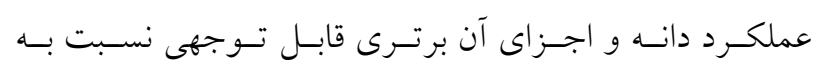

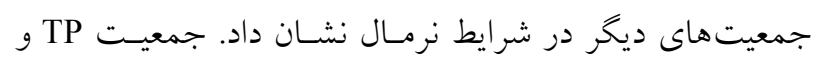

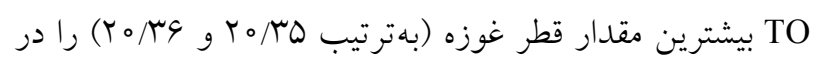

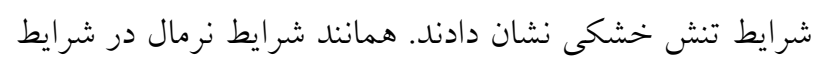

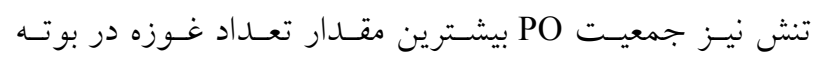

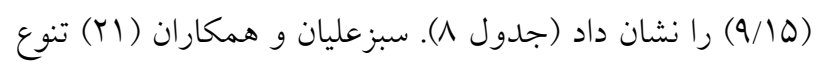
قابل ملاحظـهاى را از لحـاظ تعـداد غـوزه در بوتـه در والـــين

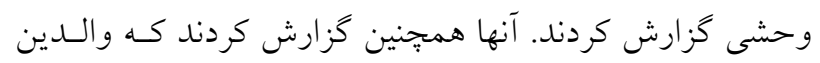

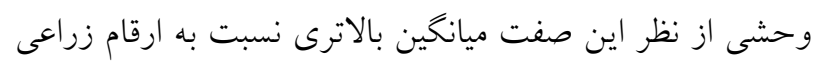

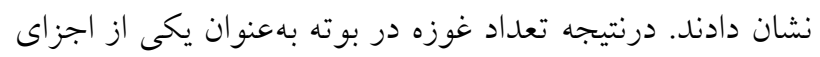

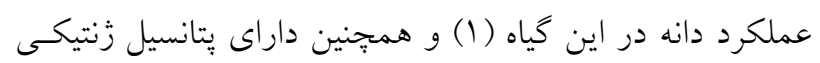

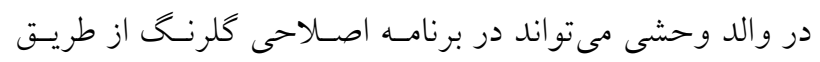

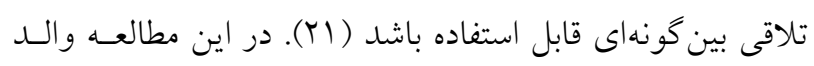
C. oxyacanthus
تعداد انشعاب در بوته (بهترتيب 1//TQ و 11/TQ) را در محسيط

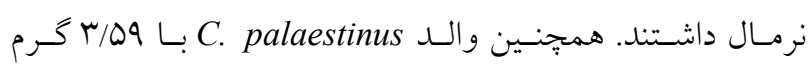

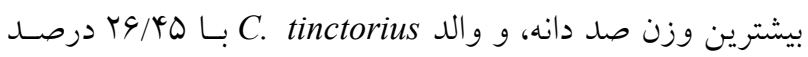
بيشترين درصد روغن رادر محيط نرمال داشتند.


بيشترين مقدار قطر غوزه (بـهترتيـب C. palaestinus

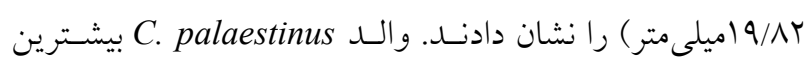

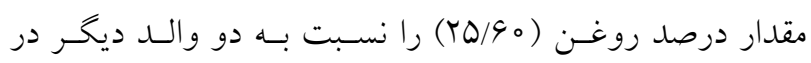

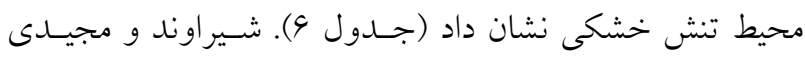

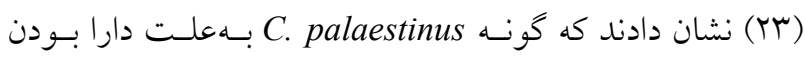

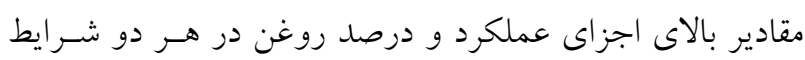

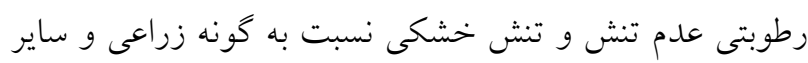

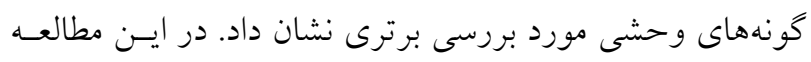

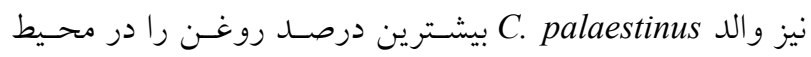

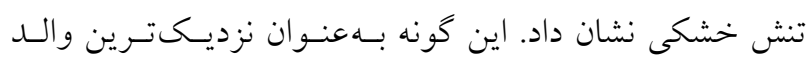

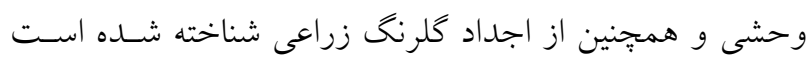

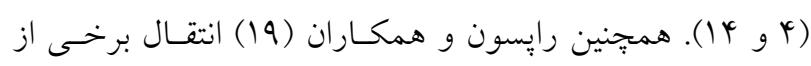

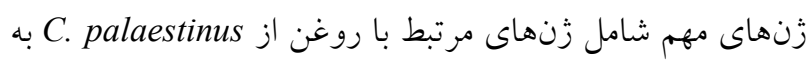
C. tinctorius

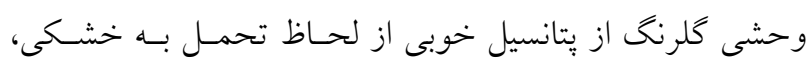

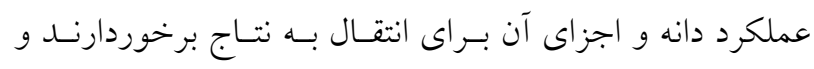

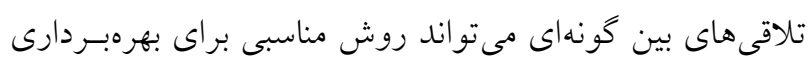

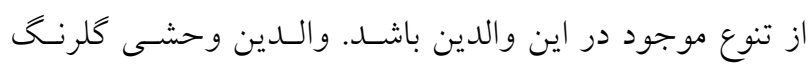

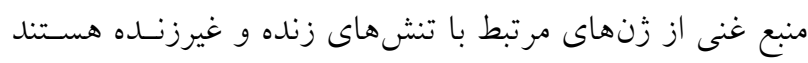

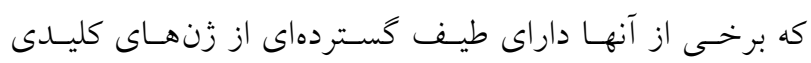

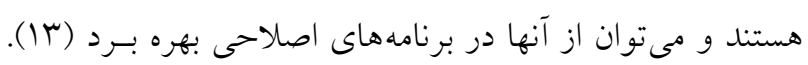

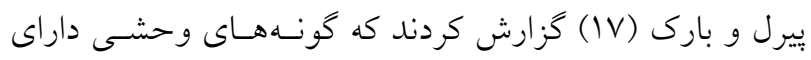

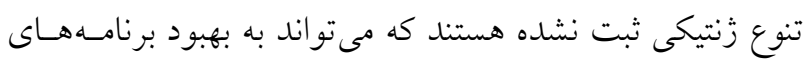

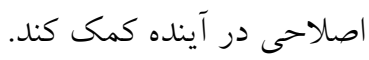

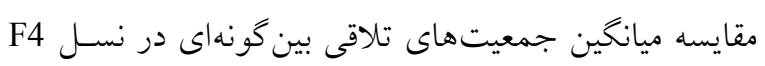

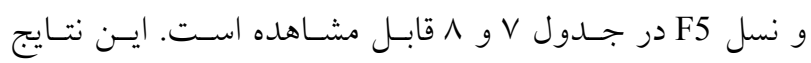

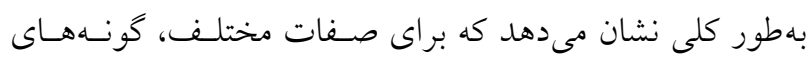


جدول V. ميانگين عملكرد دانه و اجزاى عملكرد جمعيتهاى تلاقى بين گونهاى گلرنخ در شرايط نرمال و تنش خشكى در نسل F4

\begin{tabular}{|c|c|c|c|c|c|}
\hline ميانگين & درصد تغيير & خشكى & ن & جمعيت & صفات \\
\hline $1 Y q / \Lambda^{c}$ & $Y / \Lambda 0^{*}$ & $1 T V / 99^{b}$ & $\| M \mid / 9 V^{c}$ & $\mathrm{TP}$ & \\
\hline$|r T / Y|^{a}$ & $0 / 04^{*}$ & IYN/VNa & $\mid r \Delta / g y a$ & PO & روز تا رسيدگى (روز) \\
\hline$|\mu| / \Delta^{b}$ & $Q / \Lambda r^{* *}$ & $1 T V / q_{\circ} \mathrm{b}$ & $|r Y / \Lambda|^{b}$ & TO & \\
\hline$q / 4 \Delta^{a}$ & rT/৭९्Gs & $V / 0 q^{b}$ & $11 / \mu r^{a}$ & $\mathrm{TP}$ & \\
\hline$\wedge / \wedge q^{b}$ & $r \Lambda / Y \varphi^{n s}$ & $V / \Psi^{\mathrm{c}} \mathbf{b}^{\mathrm{b}}$ & $10 / \varphi^{b}$ & PO & تعداد انشعاب در بوته \\
\hline$৭ / \wedge \Delta^{a}$ & $r M / / Q^{n s}$ & $\Lambda / 9 \Lambda^{\mathrm{a}}$ & $11 /\left.0\right|^{a b}$ & TO & \\
\hline$T Y / \Lambda K^{b}$ & $\Delta Q / \wedge Q^{*}$ & $1 \% / \circ \Lambda^{c}$ & $\Gamma Y / \Delta \Lambda^{b}$ & $\mathrm{TP}$ & \\
\hline$r Q / V Y^{a}$ & $\Delta V / \Delta 0^{*}$ & $10 / \mu y b$ & $r 4 / 0 q^{a}$ & PO & تعداد غوزه در بوته \\
\hline$r Q / 4 x a$ & 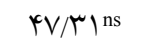 & $\mathrm{V} / \Delta \mathrm{C}^{\mathrm{a}}$ & br br/ & TO & \\
\hline$r \circ / 9 V^{a}$ & $1 \circ / \wedge^{\mathrm{ns}}$ & $19 / 49^{a}$ & $\Gamma I / \wedge \Delta^{\mathrm{a}}$ & $\mathrm{TP}$ & \\
\hline$r \circ / \circ r^{b}$ & $\mid Y / Q^{\mathrm{ns}}$ & $M / V^{\prime} b$ & $r I / r V^{b}$ & $\mathrm{PO}$ & قطر غوزه (mm) \\
\hline$r \circ / / Q^{b}$ & $I T / N^{*}$ & $\mid \Lambda / \vee \wedge^{b}$ & rI/Qrab & TO & \\
\hline$r r / \circ \circ^{a}$ & $r T / T Q^{n s}$ & $1 N / \Delta V^{a}$ & $r V / \mathcal{E} Y^{a}$ & $\mathrm{TP}$ & \\
\hline$r \circ / \mathcal{G}^{\mathrm{b}}$ & $M Y / V I^{*}$ & $19 / \mu_{\circ} \mathrm{b}$ & $Y Y / q V^{b}$ & $\mathrm{PO}$ & تعداد دانه در غوزه \\
\hline$|N / \wedge|^{c}$ & $r \mu / q r^{* *}$ & $\mid r / \Delta Y^{c}$ & $r Y / I I^{b}$ & TO & \\
\hline$Y / \Delta V^{b}$ & YY/Vqns & T/YYa & $r / 9 \circ b$ & $\mathrm{TP}$ & \\
\hline$r / T q^{c}$ & $r Y / Y q^{*}$ & $1 / \wedge \Delta^{b}$ & $T / \mu^{\mathrm{c}}$ & $\mathrm{PO}$ & وزن صد دانه (g) \\
\hline$r / V l^{a}$ & $T Y / V I^{*}$ & T/Tra & $r / \circ q^{a}$ & TO & \\
\hline$Y Y / \Delta \mu^{b}$ & $\varphi / 9 \mu^{n s}$ & $T r / q)^{b}$ & $r \Delta / 1 Q^{b}$ & $\mathrm{TP}$ & \\
\hline$r M / \Delta \mathcal{G}^{\mathrm{c}}$ & $4 / 9 q^{\mathrm{ns}}$ & $T Y / 99^{c}$ & $Y Y / 1 \varphi^{\mathrm{c}}$ & PO & درصد روغن \\
\hline$r \Delta / V Y^{a}$ & $r / \Lambda \mu^{n s}$ & $r Q / r V^{a}$ & $r 9 / 11^{\mathrm{a}}$ & TO & \\
\hline$|\Lambda \psi / \mu|^{a}$ & $\varphi \wedge / 9^{*}$ & $I Y Q / Y Y^{a}$ & YYY/YYYa & $\mathrm{TP}$ & \\
\hline$I V \circ / 9 \mu^{b}$ & $49 / v^{*}$ & $114 / \mu V^{a}$ & $T T V / D \circ b$ & PO & عملكرد دانه (gm \\
\hline $\mid V{ }^{c} / \Delta \Lambda^{b}$ & $+4 / D^{*}$ & $\mid r Y / g T^{\prime a}$ & $T Y Y / D Y b$ & TO & \\
\hline$Y Q / V I^{a}$ & $0 \circ / 9 r^{*}$ & $\mu \circ / 1 \circ a$ & $91 / \pi \mu^{a}$ & $\mathrm{TP}$ & \\
\hline$f \circ / 94 b$ & $\Delta Y / Y_{0}^{*}$ & $r \& / \Psi^{\dagger} \wedge^{b}$ & $\Delta \Delta / \uparrow_{0} b$ & $\mathrm{PO}$ & عملكرد روغن (gm $)$ \\
\hline $4 Q / / \mu^{a}$ & $Y Q / 90^{*}$ & ml/qva & $\Delta \wedge / \Delta q^{a b}$ & TO & \\
\hline
\end{tabular}

در هر ستون و براى هر صفت ميانگينهايى كه داراى حداقل يك حرف مشترى هستند برمبناى آزمون LSD تفاوت معنىدارى ندارند.

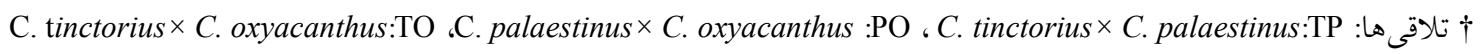

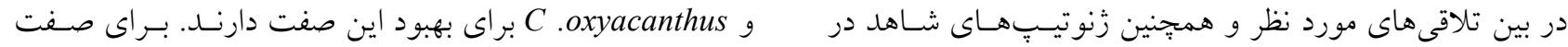
محيط تنش دارا بودند كه مىتواند تأييدى بر امكان انتقال صفت روز تا رسيدكى در محيط نرمال، بيشترين و كمتـرين ميـانخين تعداد غوزه بيشتر از والد وحشى از طريق تلاقى بسين گونسهاى و بلهترتيب مربوط به تلاقى TO و TP و داراى تفـاوت معنى دار درنتيجه انتخاب براى نتاج با تعـداد غـوزه بيشـتر در درون ايسن بودند (جدول V) ولى در محيط تنش خشكى تفاوت معنىدارى

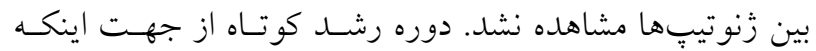

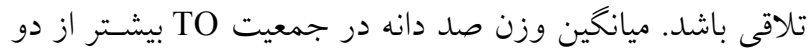

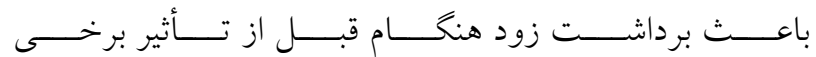
C.tinctorius جمعيت ديخر بود كه نشان دهندة بِّانسيل والدين 
جدول ^. ميانگين عملكرد دانه و اجزاى عملكرد جمعيتهاى تلاقى بين گونهاى گلرنگ در شرايط نرمال و تنش خشكى در نسل F5

\begin{tabular}{|c|c|c|c|c|c|}
\hline ميانگين & درصد تغيير & خشكى & 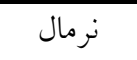 & جمعيت & صفات \\
\hline$I Y V / \Lambda^{b}$ & $\Lambda / \backslash \Lambda^{*}$ & $\mathbb{T Y} / \Gamma \Delta^{\mathrm{a}}$ & $1 \pi T / r \Delta^{c}$ & $\mathrm{TP}$ & \multirow{3}{*}{ روز تا رسيدگى (روز) } \\
\hline $\mid r \Lambda / r \omega^{a}$ & $\Lambda / 01^{*}$ & $1 Y r / 00 a$ & l & $\mathrm{PO}$ & \\
\hline ITA/TYaa & $\Lambda / \Delta \Delta^{*}$ & $|Y r / 9|^{a}$ & $\mid \mu r / \circ V^{a}$ & TO & \\
\hline $9 / 0 r^{a}$ & $Q /\left.Y\right|^{\mathrm{ns}}$ & $\varphi / \Gamma \Delta^{\mathrm{ab}}$ & $9 / \mathrm{V}^{\circ} \mathrm{a}$ & $\mathrm{TP}$ & \multirow{3}{*}{ تعداد انشعاب در بوته } \\
\hline$q / r_{\circ} b$ & $9 / 99^{\mathrm{ns}}$ & $\mathrm{Q} / 9 V^{\mathrm{b}}$ & $9 / 4 Y^{a}$ & $\mathrm{PO}$ & \\
\hline $9 / 0 \circ \mathrm{a}$ & $1 / \mu \varphi_{n s}$ & $\varphi / 4 \Delta^{a}$ & $9 / 0 Y^{\mathrm{aa}}$ & TO & \\
\hline $11 / 1 Y^{b}$ & $\Delta Y / M Y^{\mathrm{ns}}$ & $9 / 99^{b}$ & $1 Q / r \Delta^{b}$ & $\mathrm{TP}$ & \multirow{3}{*}{ تعداد غوزه در بوته } \\
\hline $1 \% / 1 \mathrm{ra}^{2}$ & $4 \varphi / 4 \varphi^{n s}$ & $9 / 10^{a}$ & $\mathrm{IV} / \circ \mathrm{qa}^{\mathrm{a}}$ & $\mathrm{PO}$ & \\
\hline $11 / q^{\mathrm{pb}}$ & $\Delta r / q V^{n s}$ & $V / \mu T^{b}$ & $10 / 9$ ab & TO & \\
\hline$Y Y / Y l^{\mathrm{a}}$ & $10 / 44^{*}$ & $r \circ / \Gamma \Delta^{a}$ & $Y Y / \circ V^{a}$ & $\mathrm{TP}$ & \multirow{3}{*}{ قطر غوزه (mm) } \\
\hline$r 1 / 1 l^{c}$ & $11 / \mathrm{VV}^{*}$ & $19 / V \wedge^{b}$ & TY/MTb & PO & \\
\hline$r 1 / 9 \circ b$ & $1 \circ / \nu^{\mathrm{ns}}$ & $r \circ /$ rqa & $r Y / \Lambda \mu^{b}$ & TO & \\
\hline$r Q / G Y^{a}$ & $M Y / 9 V^{*}$ & $r \circ / \Delta \varphi^{a}$ & $r \circ / \Delta \psi^{\prime}$ & $\mathrm{TP}$ & \multirow{3}{*}{ تعداد دانه در غوزه } \\
\hline$r M / 94 b$ & $r \varphi / 09^{*}$ & 19/1 $\mathrm{r}^{\mathrm{a}}$ & rG/A $Y^{\mathrm{b}}$ & PO & \\
\hline TY/A Y b & 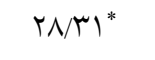 & $19 / \circ 9^{a}$ & $r \& / 09^{b}$ & TO & \\
\hline$r / 9 \varphi^{b}$ & $M / K_{0} 0^{*}$ & $T / 99 \mathrm{~b}$ & $r / r q b$ & $\mathrm{TP}$ & \multirow{3}{*}{ وزن صد دانه (g) } \\
\hline$r / \wedge V^{b}$ & $r \mid / 9 \Lambda^{*}$ & $r / \Delta Y^{b}$ & $r / r r^{b}$ & $\mathrm{PO}$ & \\
\hline$r / 19^{a}$ & $\mid Y / \Lambda G^{n s}$ & $r / 90^{a}$ & $r / 4 r a$ & TO & \\
\hline$r q / 19^{a}$ & $9 / 99^{* *}$ & $r N / / Q^{\mathrm{a}}$ & $\mu_{\circ} / / V^{a}$ & $\mathrm{TP}$ & \multirow{3}{*}{ درصد روغن } \\
\hline$r q / \wedge r^{a}$ & $\circ \circ / \mathrm{ns}^{-}$ & $r q / \wedge V^{a}$ & $r q / \wedge V^{a}$ & PO & \\
\hline$r q / r \Delta^{\mathrm{a}}$ & $Y / \Lambda \circ \mathrm{ns}$ & TN/DYa & $r 9 / 99^{a}$ & TO & \\
\hline$r \circ q / \wedge \varphi^{a}$ & $V T / Y Q^{*}$ & $91 / 19^{a}$ & $r Y \Lambda / \Delta \Delta^{a}$ & $\mathrm{TP}$ & \multirow{3}{*}{ عملكرد دانه (gm } \\
\hline r०r/raa & $94 / 91^{*}$ & $101 / \mathrm{V} \wedge^{\mathrm{a}}$ & $\mu \circ Y / \wedge r^{\mathrm{ab}}$ & PO & \\
\hline $199 / 9 \mathrm{~V}^{\mathrm{a}}$ & $G+/ \varphi^{*}$ & $1 \circ Y / 9 \Delta^{a}$ & $r q 1 / r \wedge^{\mathrm{b}}$ & TO & \\
\hline $9 \mu / 1 V^{a}$ & $V / / \Lambda I^{*}$ & $r Q / \wedge \varphi^{a}$ & $9 \Lambda / \vee \Delta^{a}$ & $\mathrm{TP}$ & \multirow{3}{*}{ عملكرد روغن (gm-2) } \\
\hline $9 l / T V^{a}$ & $9 \Lambda / V 1^{*}$ & rN/99a & $91 / 9 \circ a b$ & $\mathrm{PO}$ & \\
\hline $09 / 4 q^{a}$ & $99 / 44^{*}$ & $r q / r q a$ & $\Lambda V / \Delta \Lambda^{b}$ & TO & \\
\hline
\end{tabular}

در هر ستون و براى هر صفت ميانگينهايى كه داراى حداقل يكى حرف مشترى هستند برمبناى آزمون LSD تفاوت معنى دارى ندارند.

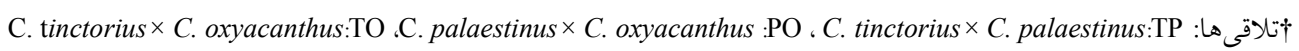

كاهش مى دهد (r). در شرايط تنش هـر سـه جمعيست يتانسـيل

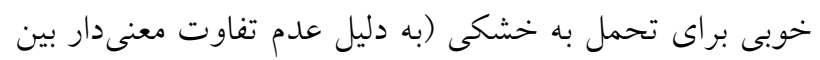

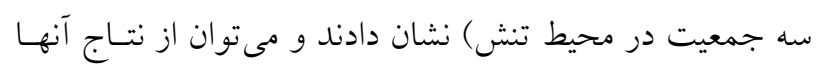

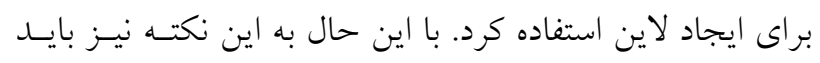

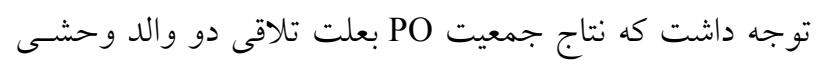

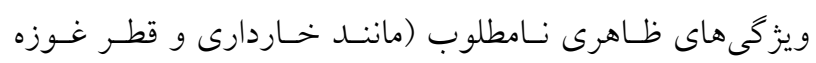

تنشهاى زنده و غيرزنده مى شود صـفتى مطلـوب بــراى ارقـام

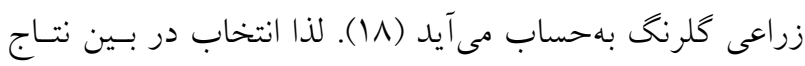



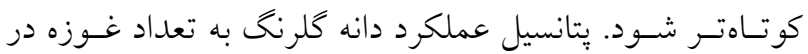

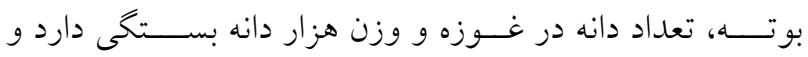

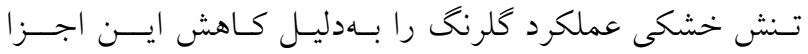



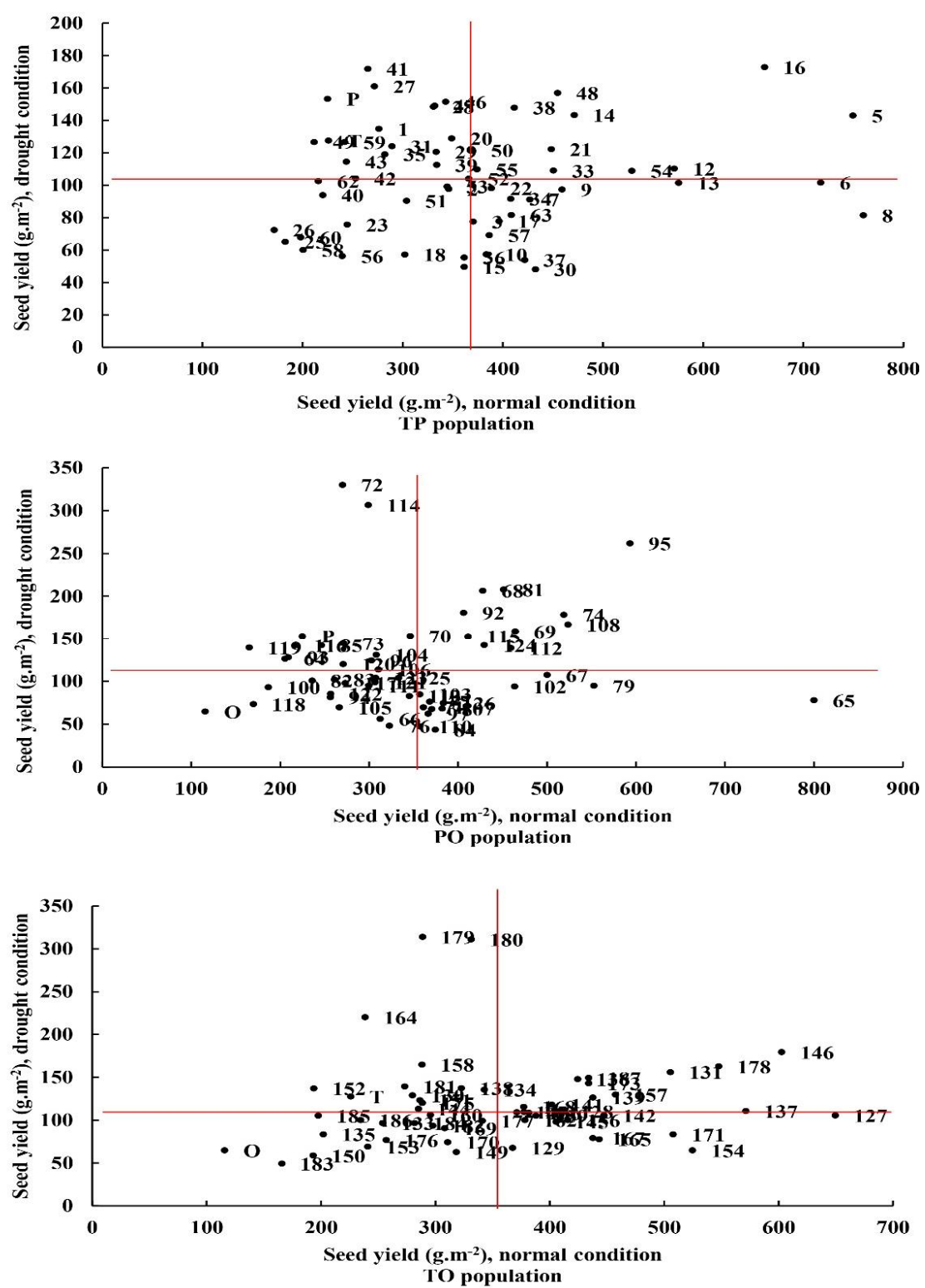

شكل ا. باىيلات عملكرد دانه در محيط نرمال در مقابل عملكرد دانه در محيط تنش براى نسل F5 در سه جمعيت تلاقى بين گونهاى گلرنغ، تلاقى ها: C. tinctorius $\times$ C. oxyacanthus:TO ،C. palaestinus $\times$ C. oxyacanthus $:$ PO ، C. tinctorius $\times$ C. palaestinus:TP. C. oxyacanthus:O C. palaestinus, :P C. tinctorius,:T :T

باىيلات عملكرد دانه در محيط نرمال در مقابل عملكرد دانـه

در محيط تنش براى نسل F5 بهلعنـوان نسـل بـا درصــ خلـوص

بيشتر براى تعيين بهترين زنوتيبها در هر جمعيت ترسـيم شـــ و

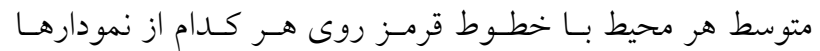

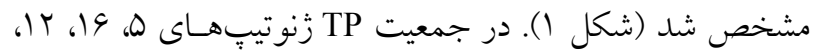

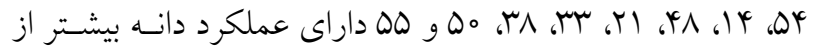

كوجى و...) بيشترى نسبت به دو جمعيت ديخر نشان مىدهند، لذا استفاده مستقيم از نتاج اين جمعيـت ممكـن اسـت مطلـوب نباشد و مىتوان از نتاج آن بهصورت غيرمستقيم و در تلاقى بـا زنوتيڤٍ هاى ديخر استفاده كرد. لذا با اصلاح به روش كام به گام

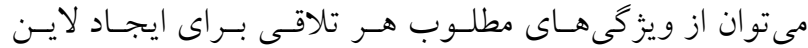
خالص بهره برد. 


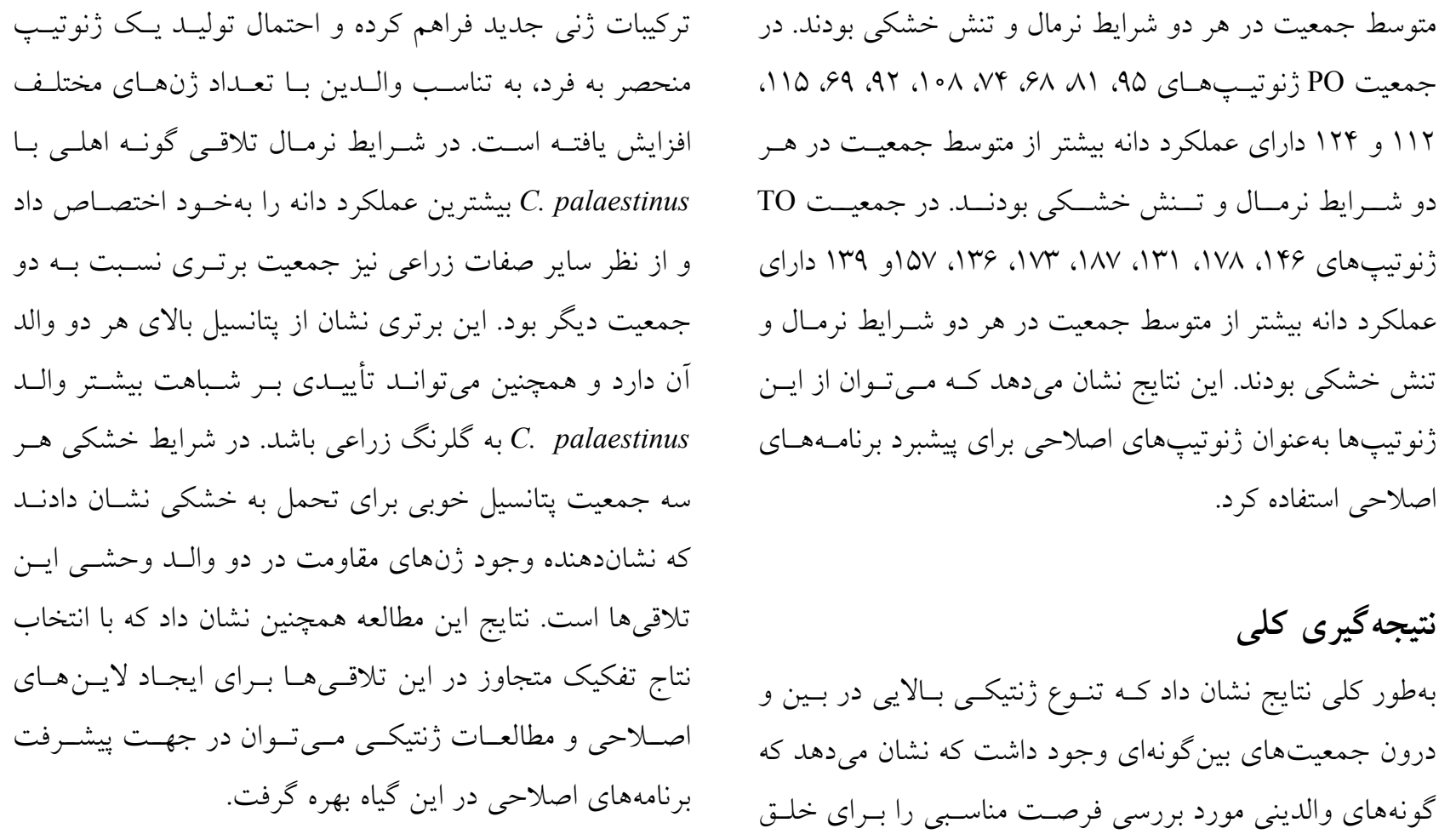

\section{منابع مورد استفاده}

1. Able, G. H. and M. F. Driscoll. 1976. Sequential trait development and breeding for high yield in safflower. Crop Science 16: 213-216.

2. Allen, R. G., L. S. Pereira, D. Raesand and M. Smith. 1998. Crop evapotranspiration guidelines for computing crop water requirements. Irrigation and Drainage 300: 7-136.

3. Ashri, A. 1975. Evaluation of the germplasm collection of safflower Carthamus tinctorius L. Distribution and regional divergence for morphological characters. Euphytica 24: 651-659.

4. Chapman, M. A. and J. M. Burke. 2007. DNA sequence diversity and the origin of cultivated safflower (Carthamus tinctorius L.; Asteraceae). BMC Plant Biology 7:60.

5. Dwevdi, K. K. and M. Gaibriyal. 2009. Assessment of genetic diversity of cultivated chickpea (Cicer arietinum L.). Asian Journal of Agriculture science 1: 7-8.

6. FAO. 2013. FAOSTAT Database. Available online at: http://faostat.fao.org.

7. Farast, M., N. Sajedi and M. Mirzakhani. 2012. Investigation of drought stress on yield and yield components of spring canola, Iran Agricultural Researches 10: 346-352. (In Farsi)

8. Farokhinia, M., M. Roshdi, B. Pasban Eslam and R. Sasandoost. 2011. Study of some physiological traits and yield in spring safflower under water deficit stress. Iranian Journal of Field Crop Science 3: 545-555. (In Farsi).

9. Hajjar, R. and T. Hodgkin. 2007. The use of wild relatives in crop improvement: A survey of developments over the last 20 years. Euphytica 156: 1-13.

10. Heaton, T. C. and J. M. Klisaewicz. 1981. A disease-resistant safflower alloploid from Carthamus tinctorius L. $\times$ C. lanatus L. Canadian Journal of Plant Science 61: 219-224.

11. Khajepour, M. R. 2005. Production of industrial plants. Isfahan University of Technology Publication Center. (In Farsi).

12. Koutroubas, S. D., D .K. Papakosta and A. Dotisinis. 2004. Cultivar and seasonal effects on the contribution of peranthesis assimilation to safflower yield. Field Crop Research 90: 244-263.

13. Majidi, M. M., V. Tavakoli, A. F. Mirlohi and M. R. Sabzalian. 2011. Wild Safflower species (Carthamus oxyacanthus Bieb.): A possible source of drought tolerance for arid environments. Australian Journal of Crop Science 5: 1055-1063.

14. Majidi M. M. and S. Zadhoush. 2014. Molecular and morphological variation in a world-wide collection of 
safflower. Crop Science 54: 2109-2119.

15. Maleki Nejad, R. and M. M. Majidi. 2015. Evaluation of Iranian and foreign safflower germplasm under normal and drought stress conditions. Journal of Crop Breeding 15: 1-13. (In Farsi).

16. Mudel, H. R., J. Morrison, R. E. Blackshow, T. Ents, B. T. Roth, R. Giudiel and F. Keihn. 1994. Seeding-date effects on yield, quality and maturity of safflower. Canadian Journal of Plant Science 74: 261-266.

17. Pearl, S. A., and J. M. Burke. 2014. Genetic diversity in Carthamus tinctorius (Asteraceae; safflower), an underutilized oilseed crop. American Journal of Botany 101: 1640-1650.

18. Poehlman, J. M. and D. A. Sleper. 1995. Breeding Field Crops. Iowa state University Press, USA.

19. Rapson, S., M. Wu, S. Okada, A. Das, P. Shrestha, X. R. Zhou, C. Wood, A. Green, S. Singh and Q. Liu. 2015. A Case study on the genetic origin of the high oleic acid trait through FAD2-1 DNA sequence variation in safflower (Carthamus tinctorius L.). Frontiers in Plant Science 6: 691-699.

20. Rao, V. R. and T. Hodgkin. 2002. Genetic diversity and conservation and utilization of plant genetic resources. Plant Cell Tissue and Organ Culture 68: 1-19.

21. Sabzalian, M. R., A. Mirlohi, G. Saeidi and M. T. Rabbani. 2009. Genetic variation among population of wild Safflower, Carthamus oxyacanthus analyzed by agro-morphological trait and ISSR markers. Genetic Resources and Crop Evolution 56: 1057-1064.

22. Saeidi, G., H. Toofi, and A. F. Mirlohi. 2004. Genetic variation and relationships among characteristics in some safflower land races of Iran. Journal of Agricultural Science and Natural Resources 15: 107-117. (In Farsi).

23. Shiravand, R. and M. M. Majidi. 2013. Trait relationships in five species of Carthamus under normal and deficit irrigation. Journal of Crop production and processing 3:149-163. (In Farsi).

24. Singh, V. and N. Nimbkar. 2007. Genetic resources, chromosome engineering, and crop improvement series. PP. 167-194, In: R. J. Singh (Eds.), Safflower (Carthamus tinctorius L.). CRC Press, London.

25. Sujatha, M. and A. G. Prabakaran. 2006. Ploidy manipulation and introgression of resistance to alternaria Helianti from wild hexaploid Heliantus species to caltivate Sunflower (H. annus L.) aided by anther calture. Euphytica 152: 201-215.

26. Yari, P., A. H. Keshtkar and A. Sepehri. 2014. Evaluation of water stress effect on growth and yield of spring safflower. Plant Production and Technologies 4: 101-117

27.Zareie, S., G. Mohammadi-Nejad and S. Sardouie-Nasab. 2013. Screening of Iranian safflower genotypes under water deficit and normal conditions using tolerance indices. Australian Journal of Crop Science 7: 1032-1037.

28. Zeynali, A. 1999. Safflower. 1 St Reprint. Gorgan University of Agricultural Sciences and Natural Resources, Gorgan, Iran. 


\title{
Evaluation of Agronomic Traits and Drought Tolerance of Safflower Lines Derived from Three Inter-Specific Crosses
}

\author{
S. Espanani ${ }^{1}$, M. M. Majidi ${ }^{\star}$, Gh. Saeidi ${ }^{2}$, H. Alaei ${ }^{3}$ and V. Rezaei ${ }^{3}$
}

(Received: July 23-2019; Accepted: January 14-2020)

\begin{abstract}
Due to genetic erosion over evolution events, the genetic diversity of domesticated safflower species for drought tolerance is limited. Wild species has been considered as useful genetic resources for improvement of abiotic stress tolerance. In this study, a cultivated species (C. tinctorius) was crossed by two wild species ( $C$. palaestinus and $C$. oxyacanthus) and the genotypes were purified until advanced generations. Then, 159 safflower recombinant lines derived from three inter-specific hybridizations were investigated during two years in terms of agronomical traits and drought tolerance at the research farm of Isfahan University of Technology. The results showed that there was considerable genetic variation in most of the agronomic and seed yield related traits among parental species and also between and within three crosses. The $C$. palaestinus and $C$. tinctorius had the highest value for seed yield under both normal and drought conditions. Under normal condition, the population derived from hybridization of cultivated species with $C$. palaestinus showed the highest seed yield and other agronomic traits. Therefore this population was superior relative to other populations. Under stress conditions, all three populations showed a potential for drought tolerance due to the inheritance of the resistance from two wild parents. In each of the three populations, transgressive segregants were identified for drought stress tolerance. Finally, the results revealed that the progenies of these crosses could be used to improve the seed and oil yield to promote this plant in arid regions.
\end{abstract}

Keywords: Inter-specific hybridization; Drought stress; Seed yield; Safflower

1, 2 and 3.PhD Student, Professors and MSc. Graduates, Respectively, Department of Agronomy and Plant Breeding, College of Agriculture, Isfahan University of Technology, Isfahan, Iran.

*: Corresponding Author, Email: majidi@iut.ac.ir 